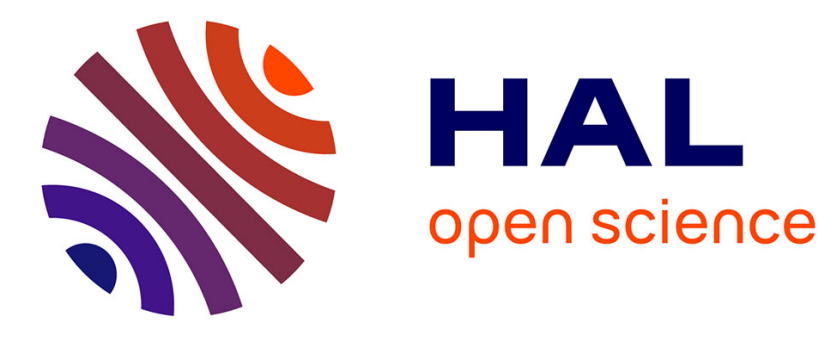

\title{
SAR Imagery for Detecting Sea Surface Slicks: Performance Assessment of Polarization-Dependent Parameters
}

Sébastien Angelliaume, Pascale C. Dubois-Fernandez, Cathleen E. Jones, Benjamin Holt, Brent Minchew, Emna Amri, Véronique Miegebielle

\section{To cite this version:}

Sébastien Angelliaume, Pascale C. Dubois-Fernandez, Cathleen E. Jones, Benjamin Holt, Brent Minchew, et al.. SAR Imagery for Detecting Sea Surface Slicks: Performance Assessment of Polarization-Dependent Parameters. IEEE Transactions on Geoscience and Remote Sensing, 2018, pp.1-21. 10.1109/TGRS.2018.2803216 . hal-01829402

\section{HAL Id: hal-01829402 https://hal.science/hal-01829402}

Submitted on 4 Jul 2018

HAL is a multi-disciplinary open access archive for the deposit and dissemination of scientific research documents, whether they are published or not. The documents may come from teaching and research institutions in France or abroad, or from public or private research centers.
L'archive ouverte pluridisciplinaire HAL, est destinée au dépôt et à la diffusion de documents scientifiques de niveau recherche, publiés ou non, émanant des établissements d'enseignement et de recherche français ou étrangers, des laboratoires publics ou privés. 


\title{
SAR Imagery for Detecting Sea Surface Slicks: Performance Assessment of Polarimetric Parameters
}

\author{
Sébastien Angelliaume ${ }^{(1)}$, Pascale Dubois-Fernandez ${ }^{(1)}$, Cathleen E. Jones ${ }^{(2)}$, Benjamin Holt ${ }^{(2)}$, \\ Brent Minchew ${ }^{(3)}$, Emna Amri ${ }^{(1)}$ and Véronique Miegebielle ${ }^{(4)}$ \\ (1) ONERA, Office National d'Etudes et de Recherches Aérospatiales \\ Département Electromagnétisme et Radar \\ BA701 13661 Salon Air cedex, France. \\ (2) Jet Propulsion Laboratory, \\ California Institute of Technology, Pasadena, CA 91125 USA \\ ${ }^{(3)}$ British Antarctic Survey, High Cross, Madingley Road Cambridge CB3 0ET, UK. \\ (4) TOTAL, CSTJF, avenue Larribau, 64018 Pau, France.
}

\begin{abstract}
Remote sensing technology is an essential link in the global monitoring of the ocean surface and radars are efficient sensors for detecting maritime pollution. When used operationally by authorities, a tradeoff must usually be made between the covered area and the quantity of information collected by the radar. To identify the most appropriate imaging mode, a methodology based on Receiver Operating Characteristic (ROC) curve analysis has been applied to an original dataset collected by two airborne systems operating at L-band, both characterized by a very low instrument noise floor. The dataset was acquired during controlled releases of mineral and vegetal oil at sea. Various polarization-dependent quantities are investigated and their ability to detect slickcovered area is assessed. A relative ordering of the main polarimetric parameters is reported in this paper. When the sensor has a sufficiently low noise floor, HV is recommended because it provides
\end{abstract}


the strongest slick-sea contrast. Otherwise $\mathrm{VV}$ is found to be the most relevant parameter for detecting slicks on the sea surface. Among all the investigated quad-polarimetric settings, no significant added-value compared to single-pol data was found. More specifically, it is demonstrated, by increasing the instrument noise level, that the studied polarimetric quantities which combine the four polarimetric channels have performances of detection mainly driven by the NESZ. This result, obtained by progressively adding noise to the raw SAR data, indicates that the polarimetric discrimination between clean sea and polluted area results mainly from the differentiated behavior between single-bounce scattering and noise.

Keywords: SAR, radar, polarization, detection, NESZ, noise floor, ocean, sea, oil, spill, slick, maritime pollution, ROC curves, probability of detection, probability of false alarm.

\section{INTRODUCTION}

Spaceborne and airborne remote sensing sensors are commonly used in the offshore domain for monitoring natural and anthropogenic oil slicks [1][2]. These sensors allow the authorities and the petroleum companies to monitor the sea shipping lanes to identify possible boat fuel releases, respond to incidents occurring at surface or subsurface oil and gas facilities, and identify the occurrence of natural hydrocarbons (seeps) on the sea surface testifying to the presence of mature source rock on the ocean bottom.

Because of the constraints linked mainly to weather conditions and the risk of significant cloud cover, the use and programming of Synthetic Aperture Radar (SAR) data is usually favored over optical imagery for oil slicks detection over the ocean surface [3]-[5]. SAR is a powerful tool for detecting hydrocarbons or chemicals on sea surface thanks to the sensitivity of the electromagnetic (EM) signal to the surface roughness. In calm seas, most of the transmitted energy is reflected away from the radar and the backscattered signal towards the instrument is very low. Wind-driven 
roughness increases the total backscatter energy from the surface. Oil films on the sea surface damp the capillary and short gravity waves that are the main source of the sea surface roughness. As a consequence, slicks appear as dark areas in the SAR image (low backscattered signal), which makes the presence of an oil slick on the sea surface detectable in radar imagery.

Several major issues are identified in the success of hydrocarbon detection in the offshore domain, the first of which remains today, the revisit time. Indeed, in an emergency situation, obtaining quick information from spaceborne sensors is decisive. This delay is constrained by the technical specificities of SAR satellite systems, the trajectory of the orbits, the location of the area of interest (there are more daily possibilities of acquisition at high latitudes than towards the equator), the data recording and downlink system and the SAR systems viewing geometry agility. Thus, very large swath modes are often selected by maritime surveillance services, to the detriment of the spatial resolution or to the amount of information potentially collected over the area of interest, like with polarimetric modes. So, monitoring services exploit mainly radar remote sensing data acquired in a single polarization mode, maximizing the covered surface of the ocean. Due to a higher backscattered signal level from the sea surface for vertically (V) polarized waves than for horizontal (H) polarization [6], the VV channel is generally preferred to the $\mathrm{HH}$ one for ocean studies. Because most of spaceborne SAR systems available today have a moderate noise floor, the crosspolarization ( $\mathrm{HV}$ or $\mathrm{VH}$ ) channels have not been used for operational ocean slick detection.

The second major issue concerns the speed of data analysis coupled with the reliability of hydrocarbon detection. Operationally, the analysis of SAR images is mostly based on the visual identification of dark areas corresponding to oil slicks. Many oceanic and atmospheric phenomena can occur over the sea surface and manifest themselves on radar images in the same way as areas covered by hydrocarbons. These are called look-alikes and they can, e.g., originate from 1) natural biogenic surface films produced by fish or plankton, 2) young and thin sea ice, 3) low wind area, and 4) upwelling of cold water. For decades, many researches have attempted to develop methodologies to differentiate ocean areas covered by hydrocarbon from look-alikes. Today, the 
discrimination between biogenic film and mineral oil remains an open subject of research. The method of conventional operational SAR analysis is mainly based on the experience and expertise of the photo-interpreter. In order to help and facilitate visual inspection, many studies have been interested in the SAR signature of hydrocarbon in different acquisition configurations to identify the optimal detection method. From an instrument point of view, the relevance of the detection depends mainly on the frequency band and the sensor noise floor. For example, it has been demonstrated in [7] that SAR images acquired at high frequency (e.g. X- or C-band) are preferable to those acquired at lower frequency (e.g. L-band) for mineral oil slick detection. In parallel with system consideration, it is essential to know what information is most relevant for detection, especially information that can be brought by the polarization of the EM waves. As many studies published in the literature have suggested that polarimetric SAR (dual-polarization or quad-polarization) parameters improve the detection capability of slicks compared to mono-polarized data, exploring the various SAR polarimetric (PolSAR) parameters accessible in the acquisition configurations is a valuable aid for operational teams in ranking the polarimetric mode to be taken into consideration. The aim of this paper is to present a prioritization of SAR parameters to enhance and facilitate slicks detection in the offshore domain. The originality of the proposed method lies in the definition and the quantitative evaluation of PolSAR parameters obtained from airborne SAR data acquired at L-band (1.325 GHz) with a very high signal to noise ratio (SNR), over controlled releases of liquid substances (including mineral and vegetal oil) at sea.

This paper is organized as follows: Section 2 summarized the state-of-the-art of PolSAR parameters proposed in the literature for slicks detection, Section 3 described the airborne SAR data used in this study, Section 4 presents the methodology used to evaluate the studied parameters and gives the results, and main discussions are in Section 5. 


\section{STATE-OF-THE-ART POLSAR PARAMETERS}

Radar remote sensing techniques are of great interest for monitoring slick covered ocean surface for two primary reasons. First, EM waves are sensitive to the modification of the sea surface induced by oil. Second, SAR sensors can be used any time and in almost any weather conditions. The physical interaction between an EM wave and a slick-covered area has been established by analyzing airborne and spaceborne data acquired over ocean surface covered by mineral oil and biogenic film [7]-[9]. Many studies have analyzed the added-value of polarimetric SAR data for slick monitoring. A useful review of polarimetric SAR parameters is given in [10] where most of the methods published in the literature for oil slicks detection are presented. Since this publication in 2012, many researchers have attempted to assess the relevance of PolSAR parameters for oil detection. These works exploit either accidental events [11] or controlled releases of oil at sea, including experiments managed by the Norwegian Clean Seas Association for Operating Companies (NOFO) in the North Sea [12]-[18]. In the following we summarize the state-of-the-art PolSAR parameters for slick detection at sea and organize the parameters by input data type.

\subsection{Dual-Polarized Synthetic Aperture Radar}

\subsubsection{Radar scattering over the ocean surface}

Over a rough sea surface where Bragg scattering is dominant (incidence angles in the socalled "plateau region", ranging from around $30^{\circ}$ to $60^{\circ}$ ), the co-polarized channels ( $\mathrm{HH}$ and VV) have higher backscatter power than the cross-polarized ( $\mathrm{HV}$ and $\mathrm{VH}$ ) channels. Higher backscattered power means higher Signal to Noise Ratio (SNR), which makes these channels more attractive for slick detection on the sea surface where typical SNR values can be low [17]. The copolarized radar backscattered power is proportional to the normalized radar cross-section (NRCS), which is defined in Bragg scattering theory [6] as

$$
\sigma_{p p}^{0}=4 \pi k_{E M}^{4} \cos ^{4} \theta_{i} \Gamma_{p p} W\left(k_{B}\right)
$$




$$
k_{B}=2 k_{E M} \sin \theta_{i}
$$

where the subscript $p$ denotes either $\mathrm{H}$ (horizontal) or $\mathrm{V}$ (vertical) polarization; $\mathrm{k}_{\mathrm{EM}}=2 \pi / \lambda_{\mathrm{EM}}$ is the electromagnetic (EM) wavenumber corresponding to the radar wavelength, $\lambda_{\mathrm{EM}} ; \Gamma_{\mathrm{pp}}$ is the reflectivity; $W\left(k_{B}\right)$ is the spectral density of the ocean surface roughness taken at the Bragg wavenumber, $k_{B}$; and $\theta_{\mathrm{i}}$ is the radar local incidence angle. The spectral density of the sea surface describes the components of the ocean wave spectrum that contribute to the scattering of the radar pulses [19], while the reflectivity describes the total power scattered from the surface. $\theta_{\mathrm{i}}$, the local incidence angle of the EM wave, is defined [6] as

$$
\theta_{i}=\cos ^{-1}[\cos (\theta+\psi) \cos \xi]
$$

where $\theta$ is the EM angle of incidence relative to the local, untilted surface vertical direction, and $\psi$ and $\xi$ are defined is the following paragraph.

The sea surface is modelled as a set of slightly rough tilted facets that contributes to the backscattering of the incident radiation. Each facet has superimposed small-scale surface roughness that creates a Bragg scattering when the roughness scale is commensurate with the radar wavelength. Small-scale roughness is randomly distributed on the scattering surface and responds to the strength of local wind, which generates capillary and short gravity waves whose wavelengths are of order centimeters to decimeters with periods less than one second [20]. The tilt of the facet is caused by larger scale gravity waves on the ocean surface that change the local orientation, or tilt, of the short waves [21]. The orientation of the facet of the sea surface is defined by two angles: $\psi$, which is the angle between local up and the projection of the facet normal onto the radar scattering plane, and $\xi$, the angle between local up and the projection of the facet normal onto the vertically oriented plane perpendicular to the scattering plane.

The co-polarized reflectivity $\left(\Gamma_{\mathrm{pp}}\right)$ is a function of the local geometry and the electrical properties of the scattering surface (e.g., seawater, films) such that 


$$
\Gamma_{p p}=\left|\left(\frac{\sin (\theta+\psi) \cos \xi}{\sin \theta_{i}}\right)^{2} \alpha_{p p}+\left(\frac{\sin \xi}{\sin \theta_{i}}\right)^{2} \alpha_{q q}\right|^{2}
$$

where the subscript $q(p \neq q)$ denotes either $\mathrm{H}$ or $\mathrm{V}$ polarization. The co-polarized Bragg scattering coefficients, introduced in (Eq. 4), are defined [6] as

$$
\begin{aligned}
& \alpha_{H H}=\frac{\cos \theta_{i}-\sqrt{\varepsilon_{r}-\sin ^{2} \theta_{i}}}{\cos \theta_{i}+\sqrt{\varepsilon_{r}-\sin ^{2} \theta_{i}}} \\
& \alpha_{V V}=\frac{\left(\varepsilon_{r}-1\right)\left(\sin ^{2} \theta_{i}-\varepsilon_{r}\left(1+\sin ^{2} \theta_{i}\right)\right)}{\left(\varepsilon_{r} \cos \theta_{i}+\sqrt{\varepsilon_{r}-\sin ^{2} \theta_{i}}\right)^{2}}
\end{aligned}
$$

They depend only on the local incidence angle of the EM wave, $\theta_{\mathrm{i}}$, and the complex-valued relative dielectric constant of the imaged surface, $\varepsilon_{\mathrm{r}}$.

The relative dielectric constant $\varepsilon_{\mathrm{r}}$, defined as the ratio between the material dielectric constant and the electric constant in a vacuum, is a complex number. Its value is material-dependent and varies with the radar frequency. It will characterize how deep an electromagnetic wave can penetrate into a conducting medium. The penetration depth, $\delta_{\mathrm{p}}$, is defined as the depth where the power of the propagating EM wave is attenuated by a factor of 1/e such that

$$
\delta_{p}=\frac{1}{2 k_{E M} \operatorname{Im}\left(\sqrt{\varepsilon_{r}}\right)}
$$

where $\operatorname{Im}($.$) select the imaginary part of a complex number. Typical values of dielectric constant of$ sea water [22] and mineral oil [23][24] are given Table 1 below. Please note that the value of dielectric constant for mineral oil is constant on the range 1-10 GHz, with a loss factor (imaginary component) close to zero, suggesting a very high penetration of the EM wave through this medium. 
TABLE I

DIELECTRIC CONSTANT OF SEA WATER FROM [22] AND MINERAL OIL FROM [23][24]

\begin{tabular}{cccc}
\hline \hline Material & $\begin{array}{c}\text { L-BAND } \\
{[1.3 \mathrm{GHz}]}\end{array}$ & $\begin{array}{c}\text { C-BAND } \\
{[5.0 \mathrm{GHz}]}\end{array}$ & $\begin{array}{c}\text { X-BAND } \\
{[10 \mathrm{GHz}]}\end{array}$ \\
\hline $\begin{array}{c}\text { Sea water } \\
\left(15^{\circ} \mathrm{C} 35 \mathrm{PSU}\right)\end{array}$ & $73.0+65.1 \mathrm{i}$ & $66.8+35.7 \mathrm{i}$ & $52.9+39.0 \mathrm{i}$ \\
Mineral oil & $2.3+0.01 \mathrm{i}$ & $2.3+0.01 \mathrm{i}$ & $2.3+0.01 \mathrm{i}$ \\
\hline \hline
\end{tabular}

Assuming a linear mixing model, the effective dielectric constant of a water-in-oil emulsion $\left(\square_{\mathrm{em}}\right)$ is given by

$$
\varepsilon_{e m}=v \varepsilon_{w}+(1-v) \varepsilon_{o i l}
$$

where $v$, ranging from 0 to 1 , is the water-content of the oil-water mixing and $\square_{\mathrm{w}}$ and $\square_{\text {oil }}$ are the relative dielectric constant of seawater and oil, respectively. It follows from (Eq. 8) that the effective dielectric constant of a mixture of oil and seawater is lower than that of seawater alone [25]. From values given Table 1 and from (Eqs. 7 and 8), the penetration depth decreases with increasing frequency and water content, with typical penetration depth of order millimeters for water contents greater than $50 \%$ (Fig. 1).

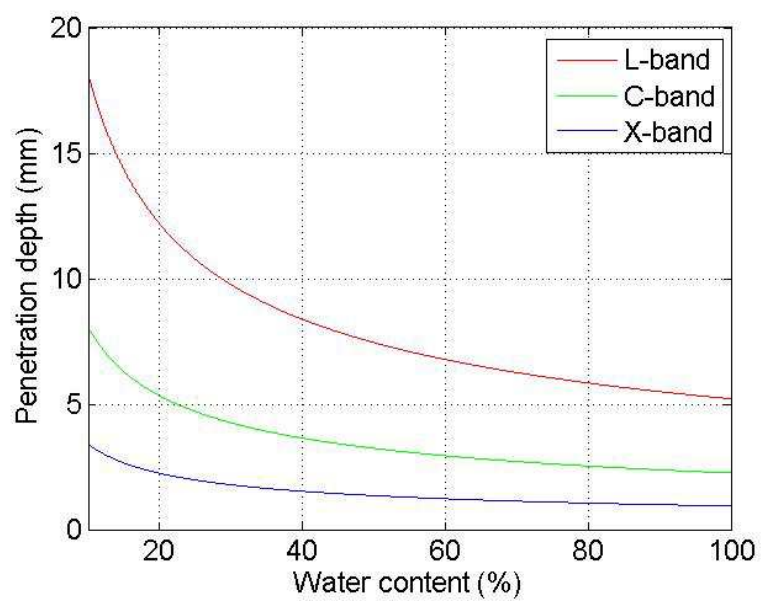

Fig. 1: Penetration depth (in millimeter) as a function of water content (linear mixing model) at Lband (red), C-band (green) and X-band (blue), dielectric constants are taken from Table1. 
When hydrocarbon is spilled into a marine environment, the oil can be mixed with seawater within the upper few centimeters of the water column or can behave like a viscoelastic film, with approximately homogenous properties, floating on the surface. In the first case (mixing), reduction of the relative dielectric constant over the contaminated sea surface compared to surrounding slickfree area will lead to a decrease in the total radar backscattered power. In the second case (film), radar backscattered power is mainly diminished through mechanical damping of Bragg-wavelength gravity-capillary waves. The capability of radar imagery to distinguish between substances that manifest as a thin film on the sea surface or that mixes with seawater near the surface has already been demonstrated in the case of mineral oil [26] and chemicals [27]. If the thickness of the film on the top of the sea surface is small compare to the penetration depth, $\delta_{\mathrm{p}}$, the EM wave will penetrate the film to scatter from the water below the film, so the effective dielectric constant will be that of seawater, and not that of the product which forms the film. When the film becomes thicker (relative to the penetration depth), the dielectric properties of the scattering medium will also impact the power of the backscattered signal.

Mineral oil films over the ocean surface can form multilayers, whose thickness can vary considerably within oil patches from less than $1 \mu \mathrm{m}$ to more than $1 \mathrm{~mm}$ [28]-[30]. When released at sea, mineral oil mixes quickly with seawater under the action of wind and waves and will result to a water-in-oil mixing with a water content generally comprised between 50 to $75 \%$ [31].

Results shown in Fig. 1 suggest that the backscattered signal from ocean surface covered by a mineral oil film will only be impacted by the dielectric properties of the medium in the case of very thick slick and preferably for high frequency imaging radar. Otherwise, damping of the sea surface roughness will be the primary mechanisms for decreasing radar backscatter power. Because the dielectric constants of biogenic films and mineral oil are similar [32][33] and because biogenic films can be observed on the ocean surface only in the form of monolayers [34], i.e., they are only one thin molecular layer (typical thickness of $2.4-2.7 \mathrm{~nm}$ ), the same phenomena will be observed 
as in the case of mineral oil film, namely reduced backscatter power caused by mechanical damping of the Bragg-wavelength surface waves with little dependence on the effective dielectric constant.

\subsubsection{Uncoherent Dual-Co-Polarized Radar Imaging System}

For maritime slick-detection methods using a dual-co-polarized (HH and VV) radar remote sensing system, the two relevant parameters that use amplitude data only are the Polarization Ratio (PR) and the Polarization Difference (PD), respectively defined (in linear units) as

$$
\begin{array}{ll}
P R=\frac{\sigma_{H H}^{0}}{\sigma_{V V}^{0}} \approx \frac{\alpha_{H H}}{\alpha_{V V}} & 0 \leq P R \leq 1 \\
P D=\sigma_{V V}^{0}-\sigma_{H H}^{0} & P D \geq 0
\end{array}
$$

As backscatter power over sea surface is stronger in VV polarization than in $\mathrm{HH}$, it follows that PR varies between 0 and 1 and PD takes positive values (as reflectivity at $\mathrm{VV}$ and $\mathrm{HH}$ are always different when the SNR is greater than $0 \mathrm{~dB}$, there are no realistic scenario in which backscattered power is nonzero and PD is equal to zero). It follows from (Eq. 9) that PR, commonly referred to as the Bragg ratio when written in this simplified form, is, in the limited presence of long waves, independent of the sea surface roughness $(W)$ and dependent only on the local incidence angle and the relative dielectric constant [26]. Since the relative dielectric constant is lower for slick-covered areas than for uncontaminated seawater, PR can detect sea surface slicks through the decrease in the relative dielectric constant. It is also considered as an attractive parameter to distinguish between slick-covered sea surface and oceanographic phenomena [17]. However, at least two major issues occur when using the Polarization Ratio (PR) for slick detection at sea. First, the contrast, which is defined as the ratio of the values obtained over contaminated and uncontaminated areas, is low. This limitation is evident in Fig. 2 where, for example, there is little difference in PR between pure seawater (line labeled 100\%) and a 50-50 mixture of oil and seawater. Furthermore, films that are thin relative to the radar wavelength (like biogenic or thin oil film) will not influence the relative dielectric constant and so will have, theoretically, no effect on PR. 


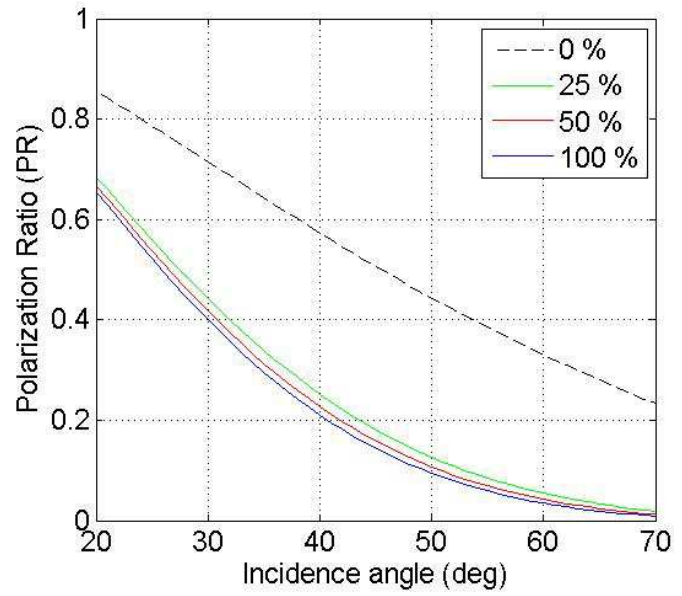

(a): PR at L-band for different values of water-content

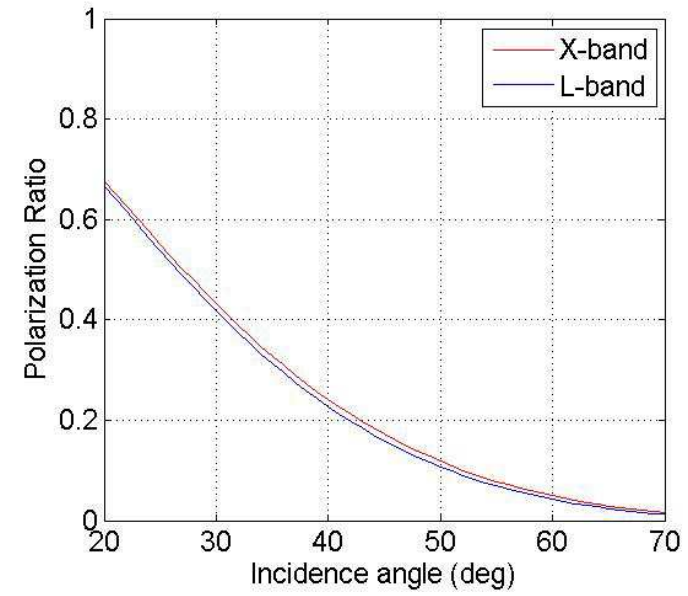

(b): PR at X-and L-band for a water content of $50 \%$

Fig. 2: Polarization Ratio (Bragg theory) as a function of incidence angle (a) at L-band for a water content of $0 \%$ (black dashed), 25\% (green), 50\% (red) and 100\% (blue) and (b) at X-band (red) and L-band (blue) for a water content of 50\%. A linear mixing is assumed between mineral oil and seawater. Values of dielectric constants are from Table 1.

The PD parameter is of interest for slicks detection at sea because it is proportional to the spectral density of the ocean surface roughness [35], which is altered even by thin films. As discussed in [36], the non-polarized part of the backscattered signal is removed using PD. Therefore, PD mostly contains contribution due to short wind-driven waves around the Bragg wavenumber (Eq. 2), making PD an attractive parameter for slick detection at sea [36].

\subsubsection{Coherent Dual-Co-Polarized Radar Imaging System}

The Polarization Difference and the Polarization Ratio, introduced above, use only the amplitude values of the complex dual-polarized signals. With a remote sensing system collecting coherent acquisition, the phase between the two co-polarized channels is measured. In this case, the following parameters are generally recommended in the literature for slick detection over the ocean surface [10]: the modulus of the co-polarized complex coherence ( $\left.\rho_{\mathrm{HHVV}}\right)$ and the Bragg Likelihood Ratio (BLR). 


$$
\begin{array}{ll}
\rho=\frac{\left\langle S_{H H} S_{V V}^{*}\right\rangle}{\sqrt{\left\langle\left. S_{H H}\right|^{2}\right\rangle \cdot\left\langle\left|S_{V V}\right|^{2}\right\rangle}}=\rho_{H H V V} e^{j \Delta \varphi} & 0 \leq \rho_{H H V V} \leq 1 \\
B L R=\max \{0, \operatorname{Re}(\rho)\} & 0 \leq B L R \leq 1
\end{array}
$$

In these equations, superscript ${ }^{*}$ denotes the complex conjugate, $\langle$.$\rangle denotes spatial averaging, \operatorname{Re}($. denotes the real part of a complex number, and $S_{p p}$ represents the complex scattering coefficient. In the case of an EM signal backscattered by rough surface, the co-polar channels (HH and VV) are correlated and in phase [6], [37]. It follows that the complex correlation of the co-polar channel is a real number (imaginary part close to zero) and the modulus ( $\left.\rho_{\mathrm{HHVV}}\right)$ takes values close to 1 . Thus, these two parameters have the same behavior, namely the value is high (close to one) when the Bragg scattering mechanism is dominant and the value is low (close to zero) otherwise. However, when the backscattered signal is corrupted by noise, the phase between the co-polar channels becomes uniformly distributed between 0 and $\pi$ and the modulus of the co-polarized coherence reaches 0 .

The polarimetric coherence between the co-polarized channels can be written as the product of three terms:

$$
\rho_{H H V V}=\rho_{\text {Scattering }} \rho_{\text {Temp }} \rho_{\text {SNR }}
$$

where $\rho_{\text {Scattering }}$ denotes the correlation between $\mathrm{HH}$ and VV due to scattering mechanism (close to 1 over ocean surface) and $\rho_{\text {Temp }}$ and $\rho_{\text {SNR }}$ denote temporal decorrelation and decorrelation due to noise, respectively. The decorrelation time of moving sea surface is of the order of $1.10^{-2} \mathrm{~s}$ at $\mathrm{X}$ band [38] and $1.10^{-1} \mathrm{~s}$ at L-band [39]. For sensors operating at low pulse repetition interval (PRI), the decorrelation due to time lag between transmitted pulses (alternatively polarized $\mathrm{H}$ and $\mathrm{V}$ ) can be neglected. For the two sensors investigated in the following (see paragraphs 3.1 and 3.2), the PRI are equal to $1.10^{-7} \mathrm{~s}$ for SETHI (operated by ONERA) and $2.3 .10^{-6} \mathrm{~s}$ for UAVSAR (operated by 
NASA/JPL), which is orders of magnitude smaller than the surface decorrelation time and assures no temporal decorrelation between $\mathrm{HH}$ and $\mathrm{VV}$ ( $\rho_{\text {Temp }}$ close to 1$)$. Thus, the only remaining decorrelation term is that induced by noise defined as

$$
\rho_{S N R}=\frac{1}{1+S N R^{-1}}
$$

This equation exhibits the strong dependence of the modulus of the co-polarized complex coherence ( $\left.\rho_{\mathrm{HHVV}}\right)$ as well as the BLR, on the SNR. Following (Eq. 14), an SNR equal to $10 \mathrm{~dB}$ (respectively 5 $\mathrm{dB}$ ) induces a decorrelation between the two co-polarized channels of $10 \%$ (respectively $25 \%$ ).

In addition to their strong dependence on the SNR, being normalized by the amplitude of the copolarized backscattering coefficient, $\rho_{\mathrm{HHVV}}$ and BLR are both more strongly affected by noise (low SNR) than the intensities alone. To overcome this limitation while exploiting the potential of these parameters, we propose to use the Hermitian Product (HP) between the two co-polarized channels, defined as

$$
H P=\left\langle S_{H H} S_{V V}^{*}\right\rangle
$$

\subsubsection{Coherent Dual-Polarized Radar Imaging System}

A way to represent polarimetric information collected by a coherent dual-polarized ( $\mathrm{HH}$ and HV or VV and VH) remote sensing system is the Stokes formalism [40]-[42]. The Stokes parameters are a set of four values $\left(\mathrm{S}_{0}, \mathrm{~S}_{1}, \mathrm{~S}_{2}, \mathrm{~S}_{3}\right)$ describing the polarization state of an EM wave:

$$
\begin{aligned}
& S_{0}=\left\langle\left|E_{H}\right|^{2}+\left|E_{V}\right|^{2}\right\rangle \\
& S_{1}=\left\langle\left|E_{H}\right|^{2}-\left|E_{V}\right|^{2}\right\rangle \\
& S_{2}=2 \operatorname{Re}\left(\left\langle E_{H} E_{V}^{*}\right\rangle\right)
\end{aligned}
$$




$$
S_{3}=2 \operatorname{Im}\left(\left\langle E_{H} E_{V}^{*}\right\rangle\right)
$$

where $\operatorname{Re}($.$) and \operatorname{Im}($.$) select the real or the imaginary value (respectively) of a complex number. E$ is the measured complex voltage in the subscripted polarization and is independent of polarization state of the transmitted wave. Using this formalism, authors have proposed to use the Degree of Polarization (DoP) for ship or maritime pollution detection [43]-[45].

$$
D o P=\frac{\sqrt{S_{1}^{2}+S_{2}^{2}+S_{3}^{2}}}{S_{0}} \quad 0 \leq D o P \leq 1
$$

Over ocean surface, the EM wave is well polarized [37] and the DoP is close to one. When the received signal is dominated by noise, as in the case for slicked surfaces imaged by most of spaceborne SARs available today, the measured signals appear depolarized and the DoP reaches values close to zero.

These last four parameters ( $\rho_{\mathrm{HHVV}}, \mathrm{BLR}, \mathrm{HP}$ and DoP), derived from co-polarized coherent acquisitions, are recommended in the literature for oil slick detection and the proposed justification comes from their ability to distinguish Bragg scattering (over clean sea surface) to another scattering mechanism that may occurs over slick-covered area. However, the impact of noise on these parameters is often omitted whereas, as we have just seen, it may have a predominant effect. An analysis of the impact of noise will be proposed in Section 4.4.

\subsection{Quad-Polarized Synthetic Aperture Radar}

Many methods using quad-polarized remote sensing data are proposed in the literature to detect ocean surface covered by a slick. For a review, the reader is referred to [10] and [46]. Here we consider a few parameters dependent on all polarizations, namely the Conformity Coefficient ( $\mu$ ), originally proposed by [47] for remote sensing application over land surfaces, the first 
eigenvalue $\left(\lambda_{1}\right)$ and the Entropy $(\mathrm{H})$ based on the eigenvalue decomposition of the covariance matrix, C [48][49].

$$
\begin{aligned}
& \mu \approx \frac{2\left(\operatorname{Re}\left(S_{H H} S_{V V}^{*}\right)-\left|S_{H V}\right|^{2}\right)}{\left|S_{H H}\right|^{2}+2\left|S_{H V}\right|^{2}+\left|S_{V V}\right|^{2}} \quad-1 \leq \mu \leq 1 \\
& C=\left[\begin{array}{ccc}
\left\langle\left|S_{H H}\right|^{2}\right\rangle & \sqrt{2}\left\langle S_{H H} S_{H V}^{*}\right\rangle & \left\langle S_{H H} S_{V V}^{*}\right\rangle \\
\sqrt{2}\left\langle S_{H V} S_{H H}^{*}\right\rangle & 2\left\langle\left|S_{H V}\right|^{2}\right\rangle & \sqrt{2}\left\langle S_{H V} S_{V V}^{*}\right\rangle \\
\left\langle S_{V V} S_{H H}^{*}\right\rangle & \sqrt{2}\left\langle S_{V V} S_{H V}^{*}\right\rangle & \left\langle\left|S_{V V}\right|^{2}\right\rangle
\end{array}\right]
\end{aligned}
$$

Over ocean, as the cross-polarized signal is very low, the conformity coefficient can be interpreted in the same way as the co-polarized coherence (Eq. 11) or the Bragg Likelihood Ratio (Eq. 12). A very simple algorithm with a threshold equal to zero is proposed in [50] for oil slick detection. The entropy has similar interpretation to that of the Degree of Polarization, but with values near zero corresponding to one dominant scattering mechanism and values close to one when multi-scattering occurs or when signal is corrupted by noise.

The main issue which occurs when working with quad-polarized SAR data is the low power of backscatter signal in the cross-polarization channels ( $\mathrm{HV}$ and $\mathrm{VH})$. For most of spaceborne SAR sensors available today, the backscattered signal measured in cross-polarization over slick-covered area is low and close to the instrument noise floor, and sometimes even lower. This strongly impacts values of polarimetric settings computed from those data.

\section{EXPERIMENTAL DATA}

Two experimental campaigns of measurements are used in this paper: NOFO'2015 and POLLUPROOF'2015. POLLUPROOF'2015 was conducted in May 2015 over the Mediterranean Sea (off the French coasts, around $42^{\circ} 45^{\prime} \mathrm{N}, 5^{\circ} 45^{\prime} \mathrm{E}$ ) and focused on the release and subsequent 
observation of several hazardous and noxious substances (HNS) that are meant to represent the majority of chemicals commonly transported by sea. The primary goal of this experiment is to establish a procedure for collecting evidence of illegal maritime pollution by HNS using airborne sensors [27]. SAR imageries over controlled releases of Fatty Acid Methyl Esters (FAME) and rapeseed oil, conducted during the POLLUPROOF'2015 experiment, are investigated in this study (Table 2). Vegetal oils (like plant oil or rapeseed oil) have already been imaged by SAR sensors as they are often used to simulate a natural monomolecular biogenic slick [9][12]. NOFO'2015 was conducted from the $8^{\text {th }}$ to the $14^{\text {th }}$ of June 2015 during NOFO's oil-on-water exercise. This experiment aims at testing recovering systems of pollution at sea by hydrocarbons. During the exercise, airborne and spaceborne acquisitions were collected over the offshore spill areas (North Sea, around $59^{\circ} 59^{\prime} \mathrm{N}, 2^{\circ} 27^{\prime} \mathrm{E}$ ). In the following, we focus on SAR imageries collected by the French and American airborne sensors on the $9^{\text {th }}$ of June 2015. For the investigated experiment, the released product is an emulsion of mineral oil in water, with a water content of $60 \%$ (Table 2). It consists of a mix of water, Oseberg crude oil and a small addition of IFO 380 (Intermediate Fuel Oil or marine diesel oil, with viscosity of $380 \mathrm{~mm}^{2} \cdot \mathrm{s}^{-1}$ ). For the trial, $45 \mathrm{~m}^{3}$ of mineral oil emulsion were discharged at sea. Large swath remote sensing data collected by UAVSAR (see 3.2), allows to measure the full extent of the hydrocarbon-covered area, namely $5.4 \mathrm{~km}^{2}$. Assuming all the $45 \mathrm{~m}^{3}$ of mineral oil emulsion released at sea was on the surface, one can estimate the upper limit of the average slick thickness, namely $8.3 \mu \mathrm{m}$. The effective thickness is lower, modeling achieved the $10^{\text {th }}$ of June, during another spill exercise and for higher winds, indicates that only about $50 \%$ of the released oil was on the surface a few hours after the released [51]. 
TABLE II

ENVIRONMENTAL CONDITIONS AND PROPERTIES OF RELEASED SUBSTANCES.

\begin{tabular}{cccccccc}
\hline \hline $\begin{array}{c}\text { Date of } \\
\text { release }\end{array}$ & $\begin{array}{c}\text { Time of } \\
\text { release } \\
\text { (UTC) }\end{array}$ & $\begin{array}{c}\text { Amount of } \\
\text { release }\end{array}$ & $\begin{array}{c}\text { Released } \\
\text { substance }\end{array}$ & $\begin{array}{c}\text { Time of } \\
\text { imaging } \\
\text { (UTC) }\end{array}$ & $\begin{array}{c}\text { Wind } \\
\text { speed } \\
\text { (m/s) }\end{array}$ & $\begin{array}{c}\text { Wind } \\
\text { direction } \\
\text { from-deg) }\end{array}$ & $\begin{array}{c}\text { Wave } \\
\text { height (m) } \\
\text { imaging }\end{array}$ \\
\hline $\begin{array}{c}\text { 22 May, } \\
\text { 2015 }\end{array}$ & $15: 00-15: 30$ & $1 \mathrm{~m}^{3}$ & Rapeseed oil & $16: 07$ & 7 & 315 & 2 \\
$\begin{array}{c}\text { 22 May, } \\
\text { 2015 }\end{array}$ & $15: 25-15: 40$ & $1 \mathrm{~m}^{3}$ & FAME & $16: 07$ & 7 & 315 & 2 \\
$\begin{array}{c}\text { 09 June, } \\
\text { 2015 }\end{array}$ & $06: 30-08: 00$ & $45 \mathrm{~m}^{3}$ & Mineral oil & $09: 56$ & 5 & 270 & 1 \\
09 June, \\
2015
\end{tabular}

The methodologies and the results presented in the following are based on SAR data collected by SETHI, the remote sensing imaging system developed by ONERA, as well as experimental data acquired by UAVSAR, the airborne sensor of JPL/NASA. Sections 3.1 and 3.2 below briefly present the two SAR systems used here. Table 3 summarizes all SAR scenes investigated in this paper.

TABLE III

PROPERTIES OF SAR SCENES INVESTIGATEd IN THIS STUDY. INCIDENCE ANGLE AND NESZ VALUES ARE THE MinimUM AND MAXIMUM ACROSS THE IMAGING SWATH.

\begin{tabular}{cccccccc}
\hline \hline Sensor & $\begin{array}{c}\text { Frequency } \\
\text { band }\end{array}$ & $\begin{array}{c}\text { Polarization } \\
\text { mode }\end{array}$ & Experiment & Date & $\begin{array}{c}\text { Time } \\
(\mathrm{UTC})\end{array}$ & $\begin{array}{c}\text { Incidence } \\
\text { angle } \\
(\mathrm{deg})\end{array}$ & $\begin{array}{c}\mathrm{NESZ} \\
\left(\mathrm{dBm}^{2} / \mathrm{m}^{2}\right)\end{array}$ \\
\hline SETHI & L & Quad-Pol & POLLUPROOF & $\begin{array}{c}22 \mathrm{May}, \\
2015\end{array}$ & $16: 07$ & $34 / 52$ & $-51 /-53$ \\
SETHI & L & Quad-Pol & NOFO & $\begin{array}{c}\text { 09 June, } \\
\text { 2015 }\end{array}$ & $10: 01$ & $34 / 52$ & $-51 /-53$ \\
UAVSAR & L & Quad-Pol & NOFO & $\begin{array}{c}\text { 09 June, } \\
\text { 2015 }\end{array}$ & 09:56 & $19 / 51$ & $-45 /-51$ \\
\hline \hline
\end{tabular}

\subsection{SETHI: Airborne Quad-Polarized SAR Sensor}

SETHI is the ONERA airborne remote sensing laboratory designed to explore the science applications of remote sensing [52]. It is a pod-based system operating onboard a Falcon 20 Dassault aircraft, flying at an altitude of $9000 \mathrm{ft}$. 
For both POLLUPROOF'2015 and NOFO'2015 campaigns, quad-polarized SAR data were acquired at L-band, with a range resolution of $1.0 \mathrm{~m}$ (bandwidth from 1.25 to $1.4 \mathrm{GHz}$ ). Images are processed with an azimuth (along-track) resolution equal to the range resolution. Imaged area is 9.5 $\mathrm{km}$ in azimuth and $1.5 \mathrm{~km}$ in range, with incidence angles from $34^{\circ}$ to $52^{\circ}$. The instrument noise floor has been estimated using the method proposed in [53] and the results are shown in Fig. 3 below. The estimated NESZ is very low, ranging from around -51 to $-53 \mathrm{~dB}$, allowing a sufficiently high SNR over slick-covered areas for valid analysis of surface characteristics. Examples of high resolution PolSAR images acquired by SETHI at L-band are shown in Section 4.

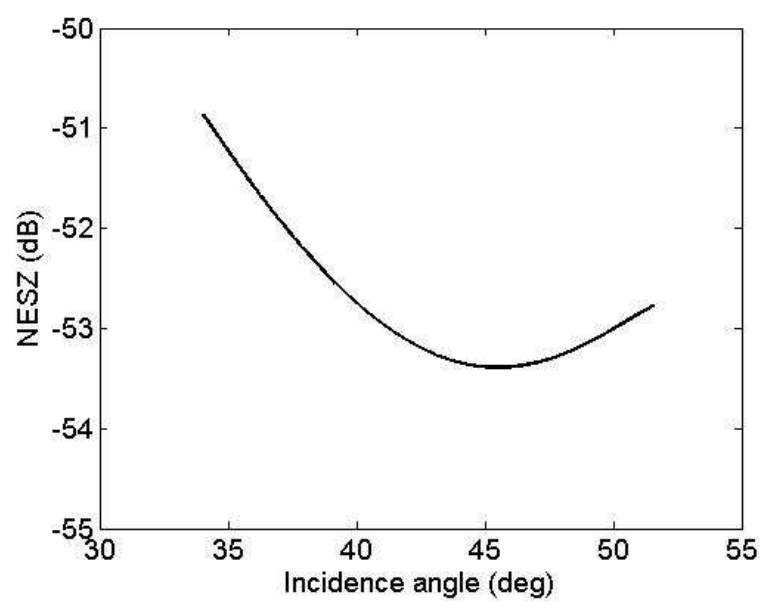

Fig. 3: SETHI - POLLUPROOF'2015 and NOFO'2015 experiment - Instrumental noise floor.

\subsection{UAVSAR: Airborne Quad-Polarized SAR Sensor}

During the NOFO'2015 experiment, UAVSAR (Uninhabited Aerial Vehicle Synthetic Aperture Radar, developed by NASA [54]) acquired quad-polarized SAR data at L-band over controlled releases of mineral oil at sea, flying at an altitude of $35100 \mathrm{ft}$. The data used in this analysis were acquired on 9 June 2015, within 5 minutes of SETHI and over the same area. They are processed with a resolution of $5 \mathrm{~m}$ in range and $7.2 \mathrm{~m}$ in azimuth (multi-look format). The incidence angle ranges from $19^{\circ}$ to $51^{\circ}$ across the swath. The instrument noise floor has been estimated using the same methodology as for the SETHI one [53] and it is shown in Fig. 4. The 
NESZ is very low, ranging from around -45 to $-51 \mathrm{~dB}$, allowing as for SETHI a sufficient SNR over sea surface covered by slicks for valid analysis of surface properties.

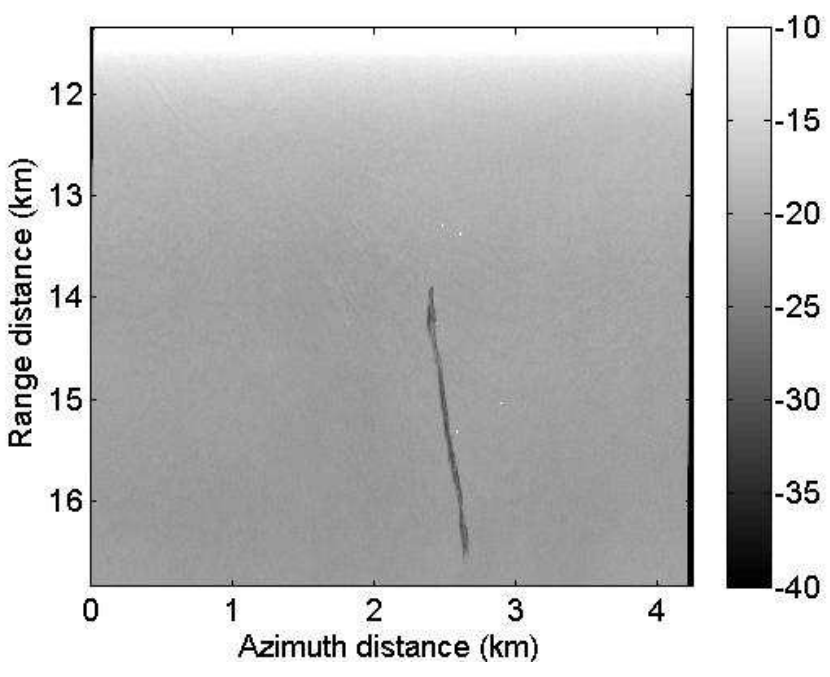

(a): UAVSAR - VV polarization - NOFO'2015

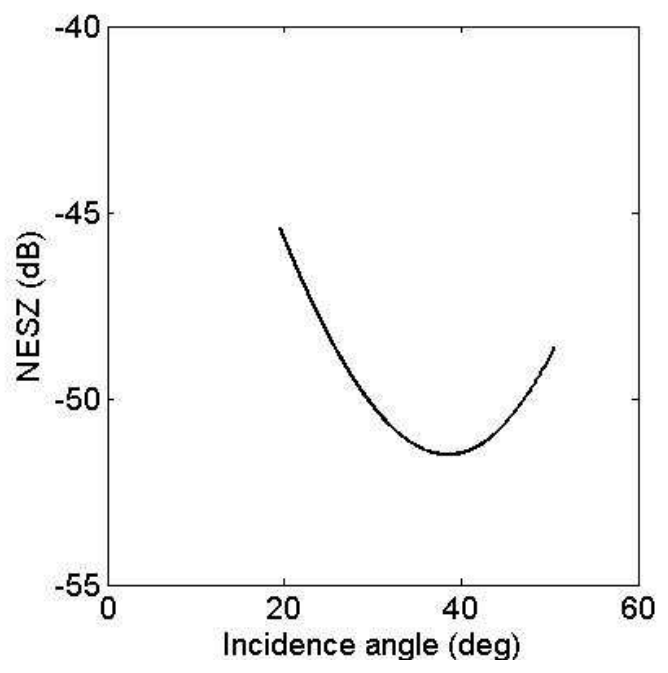

(b): UAVSAR - NESZ

Fig. 4: UAVSAR - NOFO'2015 experiment, June 09, 2015 09:56 UTC - VV image (a) and instrumental noise for the corresponding acquisition (b). The oil slick is located at incidence angle $\sim 40$ to $50^{\circ}$ in the image.

The literature on remote sensing over maritime pollution is very prolific and we can find many illustrations of airborne or spaceborne SAR imagery over oil slicks but none have compared multiple low NESZ instruments operating in the same band with near simultaneous imaging the same slick, which is done herein.

\section{METHODOLOGY AND PERFORMANCE ASSESSMENT}

We use Receiver Operating Characteristic (ROC) curves to characterize the detection capabilities of the polarimetric parameters discussed in Section 2 [55]. This is an extension of the methodology published in [13] using a much larger dataset and a more comprehensive set of parameters. ROC curves are obtained by plotting the probability of detection (Pd) against the 
probability of false alarm (Pfa), and they quantify the performance of a detector as its discrimination threshold is varied. In other words, ROC graphs depict the trade-off between hit rates and false alarm rates of detectors [55]. The procedure is as follows (Fig. 5): we manually select areas of clean sea surface (i.e. the background) and slick (i.e. the area of interest) and compute for each investigated polarimetric parameters the histograms of values within the two regions. Then, for all possible values of the detection threshold, we calculate $\mathrm{Pd}$ as the fraction of samples in within the area of interest that exceed the threshold and Pfa as the fraction of samples in the background that are below the threshold. We will use these results to develop an instrument-independent ranking of the detection capabilities of each polarimetric parameter.

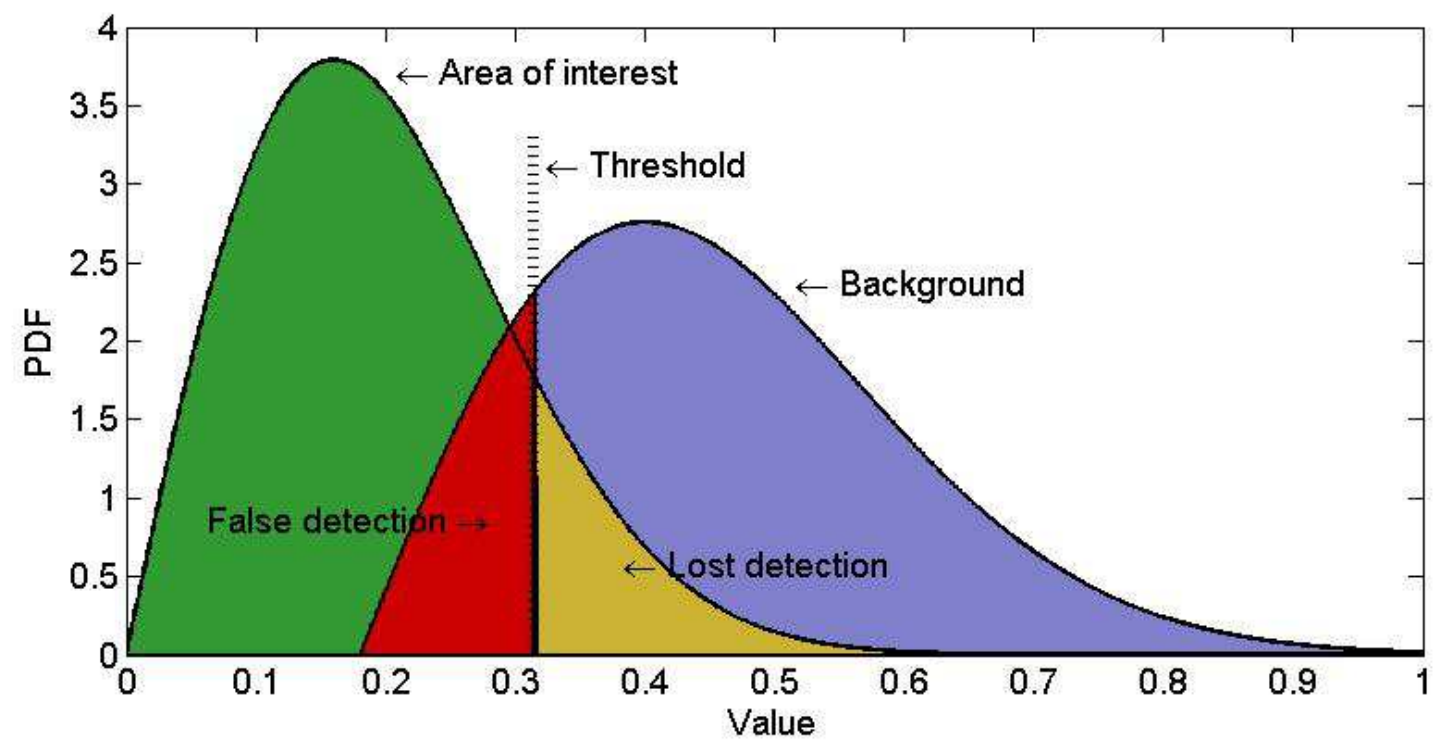

Fig. 5: Overview of histogram thresholding for ROC curves computation based upon separation of two classes.

\subsection{Sea Surface Slicks Observation}

We begin by evaluating the quad-pol SAR data acquired by SETHI (Fig. 6) over a controlled release of mineral oil (NOFO'2015 experiment). For these images, the wind direction is from the top right. Wind information was obtained from the Norwegian Meteorological Institute and is given 
in Table 2. The oil slick is observable as a dark area, with a ship's wake running through the slick.

Within the lower part of the slick, the passage of a mechanical recovery boom (MOS Sweeper [56]) appears to have left a relatively clean sea surface. Images show a feathered structure along the top of the slick, due to the effect of the wind.

Interestingly, while the upper limit of the slick thickness $(8.3 \mu \mathrm{m})$ has been estimated to be at least one-hundredth of the penetration depth at L-band (typically of order millimeters for water content greater than 50\% - see. Fig. 1), the mineral oil slick is observable in the PR images (Fig. 6 - (d)).

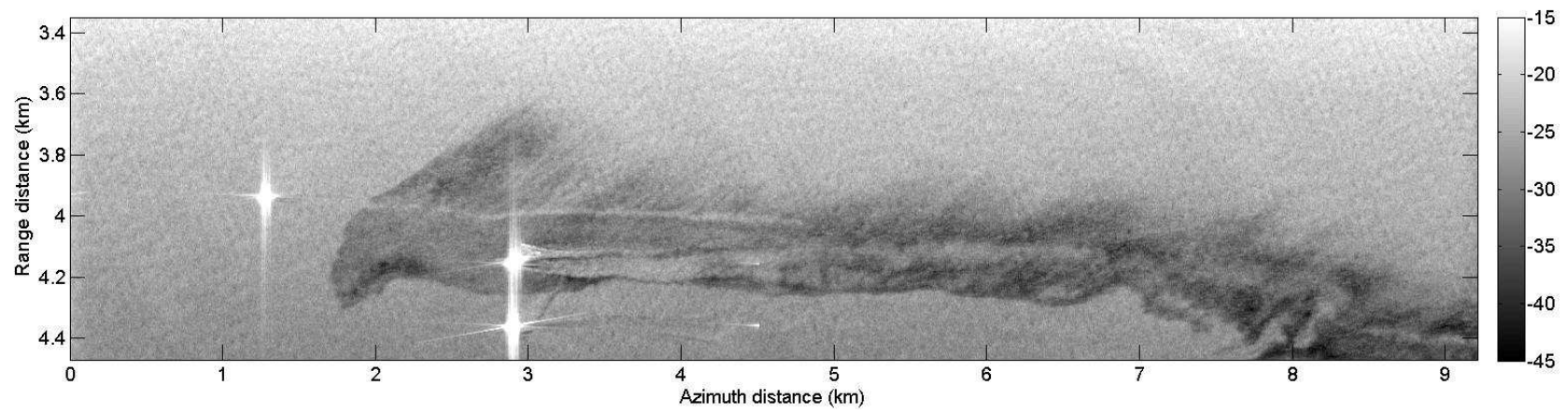

(a): SETHI, L-HH, NOFO'2015, 09 June 2015, 10:01 UTC

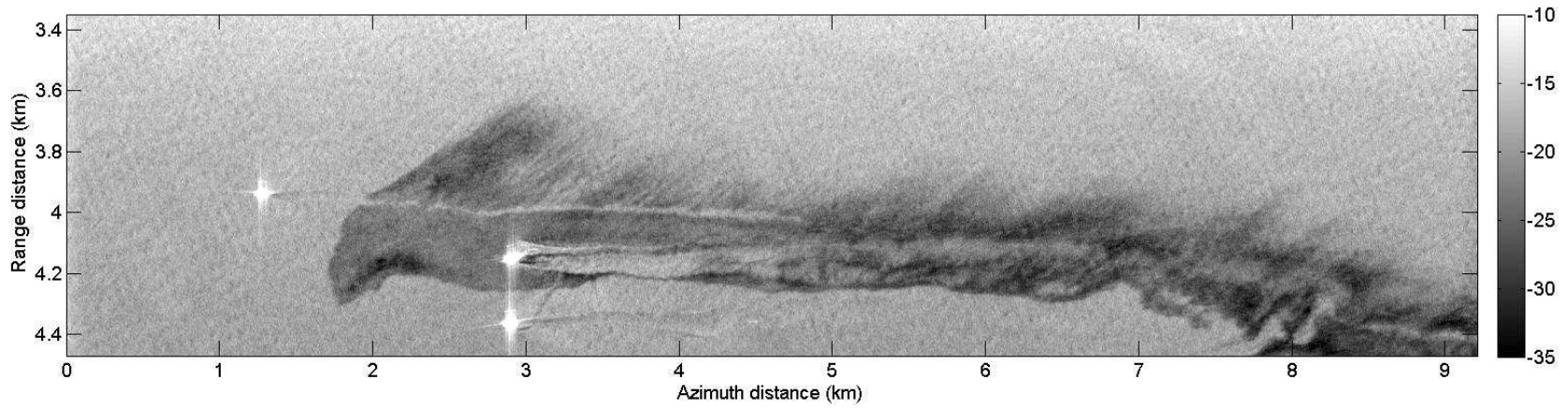

(b): SETHI, L-VV, NOFO'2015, 09 June 2015, 10:01 UTC

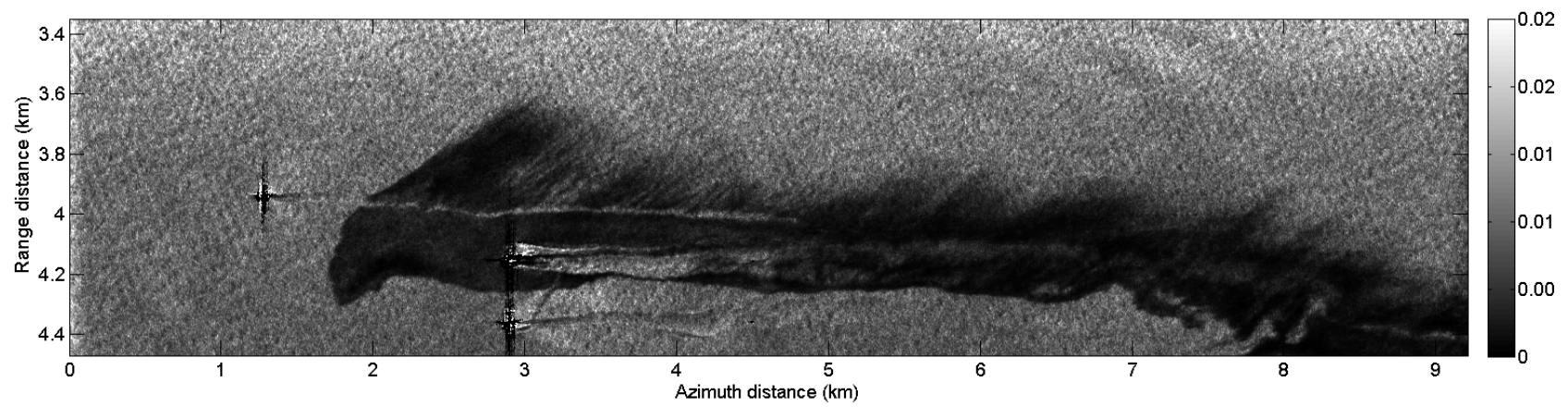

(c): SETHI, L-PD, NOFO'2015, 09 June 2015, 10:01 UTC 


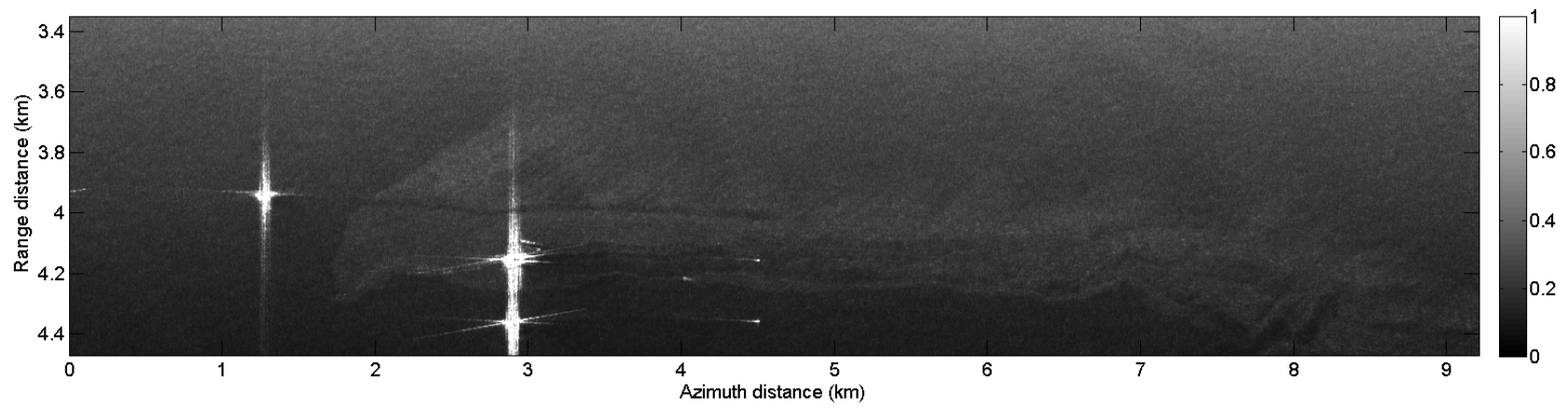

(d): SETHI, L-PR, NOFO'2015, 09 June 2015, 10:01 UTC

Fig. 6: SETHI NOFO'2015 - L-band SAR data acquired over mineral oil released at sea - June 09, 2015 - 10:01 UTC - HH (a), VV (b), PD (c) and PR (d) quantities - multi-look 7x7.

Low backscattering values from slick covered areas can lead to low SNR values. Therefore, it is critical that we ensure sufficiently high SNR values before undertaking any analysis. SNR values along a transect through data obtained by SETHI during the NOFO'2015 experiment is shown in Fig. 7. The curves have been computed across a range transect at azimuth $2.1 \mathrm{~km}$. The slick is between $3.85 \mathrm{~km}$ (incidence angle $44.2^{\circ}$ ) and $4.2 \mathrm{~km}$ (incidence angle $49.4^{\circ}$ ). The $\mathrm{SNR}$ values are high (even in cross-polarization) to allow for polarimetric analysis of the surface properties.

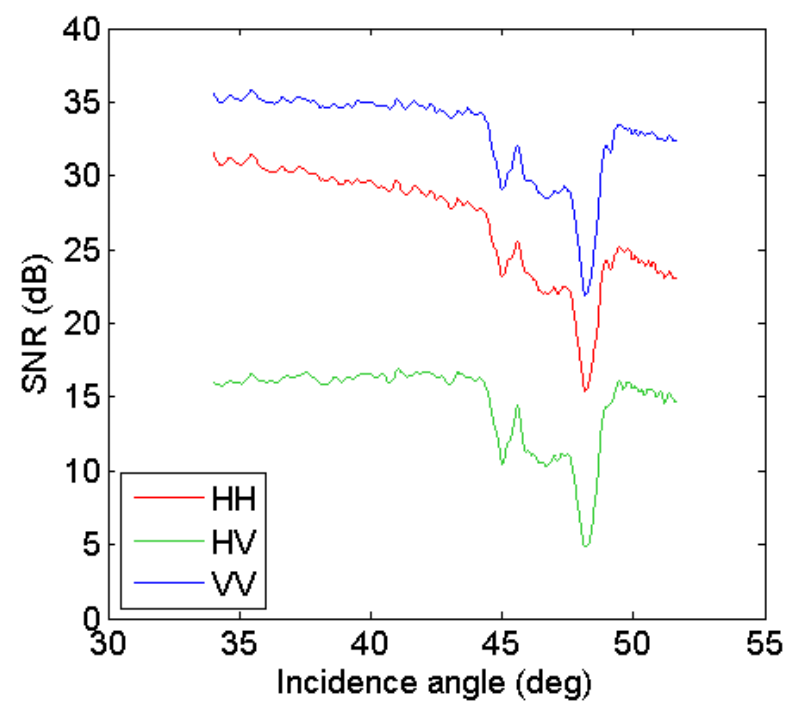

Fig. 7: SETHI Signal to Noise Ratio (SNR) in polarization HH (red), HV (green), VV (blue) Range transect for azimuth $2.1 \mathrm{~km}$ (see. Fig. 6) - June 09, 2015 - 10:01 UTC 
We first focus on SAR data collected by SETHI over mineral oil spill (NOFO'2015 experiments). Fig. 8 shows areas selected for ROC curves computation where the uncontaminated sea surface (background) is outlined by the blue box and the contaminated area of interest is outlined by the red box. Note that the average SNR computed over the two regions (Table 4) is at least equal to $10 \mathrm{~dB}$.

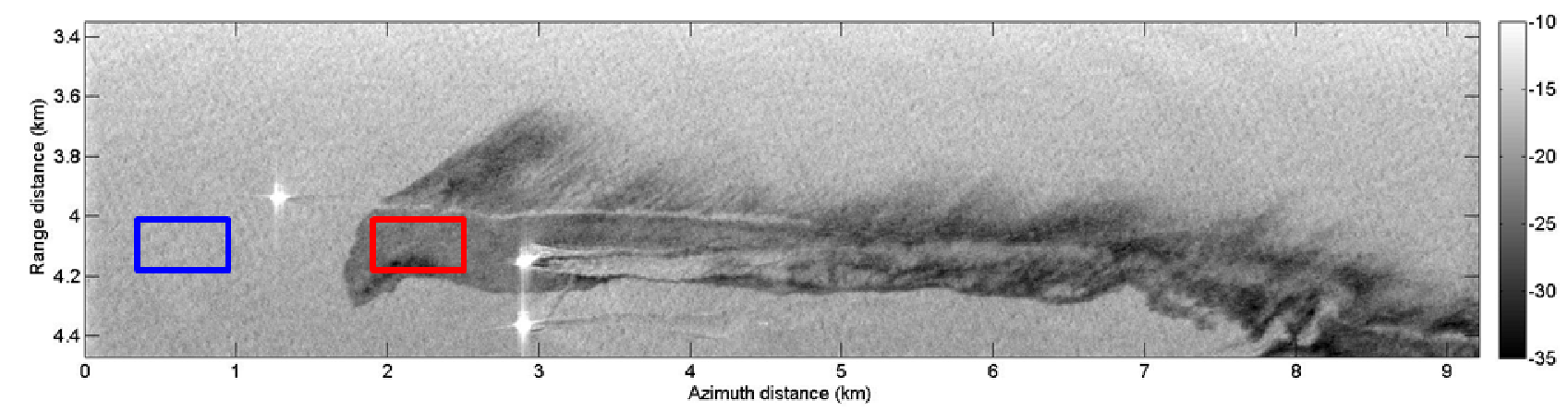

Fig. 8: Areas selected for ROC curves computation - blue box: clean sea surface, red box: slick area - SETHI, NOFO'2015 experiment, June 09, 2015 10:01 UTC - multi-look 7x7.

TABLE IV

SIGNAL TO NOISE RATIO - SETHI, NOFO'2015 EXPERIMENT, 09 JUNE 2015 10:01 UTC

\begin{tabular}{ccccc}
\hline \hline Region & $\begin{array}{c}\text { Incidence } \\
\text { angle (deg) }\end{array}$ & $\mathrm{HH}$ & $\mathrm{HV}$ & $\mathrm{VV}$ \\
\hline Clean sea & $44.5^{\circ}$ & $26.5 \mathrm{~dB}$ & $16.4 \mathrm{~dB}$ & $34.1 \mathrm{~dB}$ \\
Oil slick & $44.5^{\circ}$ & $21.5 \mathrm{~dB}$ & $10.2 \mathrm{~dB}$ & $28.0 \mathrm{~dB}$ \\
\hline \hline
\end{tabular}

ROC curves (Fig. 9) shows that PD and VV are the most efficient parameters for mineral oil slicks detection (i.e. for a given value of Pfa, they exhibit the greater value of Pd). HV has good performance of detection and is better than $\mathrm{HH}$ for low values of Pfa. This result for HV, which is consistent with results obtained with UAVSAR data in stronger wind conditions [18], is possible because of high SNR over the entire image. Then, we found that most of the quad-polarimetric parameters have low Pd values for all Pfa values. These results seem to indicate that the same main 
scattering mechanism occurs over both contaminated and uncontaminated sea surface, namely surface reflection and Bragg scattering [25]. To confirm this, we note that the polarimetric Entropy, computed with a high SNR even over polluted area, is low both over clean sea surface and area covered by oil: mean entropy values are respectively equal to 0.18 and 0.17 . This indicates that only one dominant scattering mechanism occurs, which confirms previous observations [16][18] for the NOFO'2015 exercise and the original observation based on UAVSAR L-band data acquired over the Deepwater Horizon oil spill accident [25].
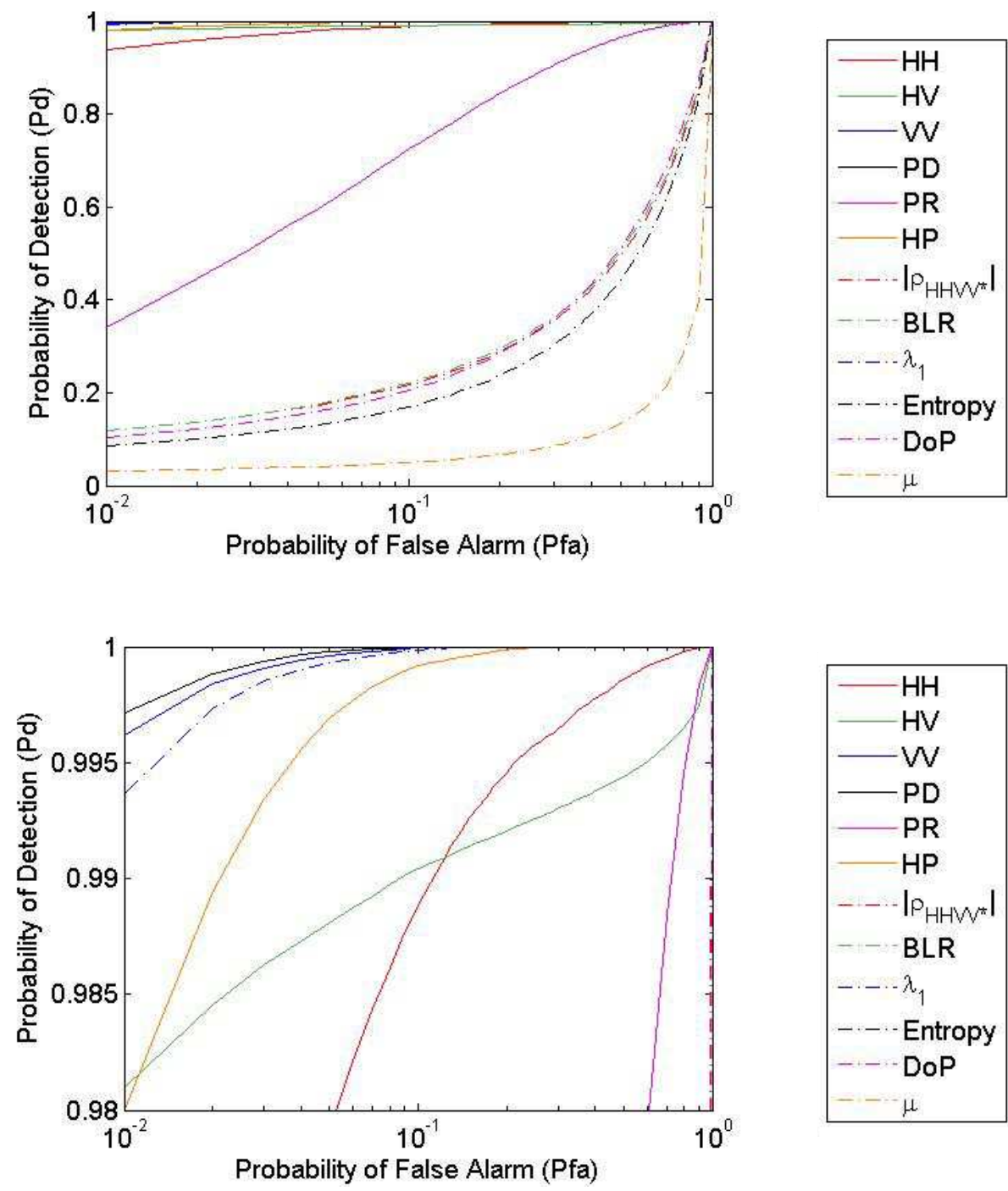

Zoom of the above figure for Pd greater than $98 \%$ 
Fig. 9: Probability of Detection (Pd) vs Probability of False Alarm (Pfa) computed for all investigated parameters - The top figure is a zoom of the above figure for Pd greater than $98 \%$.

SETHI, NOFO'2015 experiment, June 09, 2015 10:01 UTC

We now investigate SAR data collected with UAVSAR during the same NOFO'2015 experiment (mineral oil). As for SETHI, the UAVSAR instrument is characterized by a very low noise floor, which suggests a good complementarity of the results obtained with the two airborne sensors. The imaged ocean surface is the same as for the previous SETHI analysis (Fig. 8) and the time lag between the two acquisitions is only equal to 5 minutes. For UAVSAR ROC graphs analysis, contaminated and clean sea surface are close to those selected for SETHI (Fig. 8 and Fig. 10). The NESZ is optimal (areas choosen close to the middle of the swath) and Signal to Noise Ratio corresponding to the selected regions are given Table 5. As for SETHI, the levels are very high (at least $7 \mathrm{~dB}$ ), which ensures a relevant analysis over both slick-free and oil-covered sea surfaces.

TABLE V

SIGNAL TO NOISE RATIO - UAVSAR, NOFO'2015 EXPERIMENT, 09 JUNE 2015 09:56 UTC

\begin{tabular}{ccccc}
\hline \hline Region & $\begin{array}{c}\text { Incidence } \\
\text { angle (deg) }\end{array}$ & $\mathrm{HH}$ & $\mathrm{HV}$ & $\mathrm{VV}$ \\
\hline Clean sea & $40.6^{\circ}$ & $17.8 \mathrm{~dB}$ & $11.4 \mathrm{~dB}$ & $26.7 \mathrm{~dB}$ \\
Oil slick & $40.6^{\circ}$ & $13.4 \mathrm{~dB}$ & $6.8 \mathrm{~dB}$ & $20.2 \mathrm{~dB}$ \\
\hline \hline
\end{tabular}




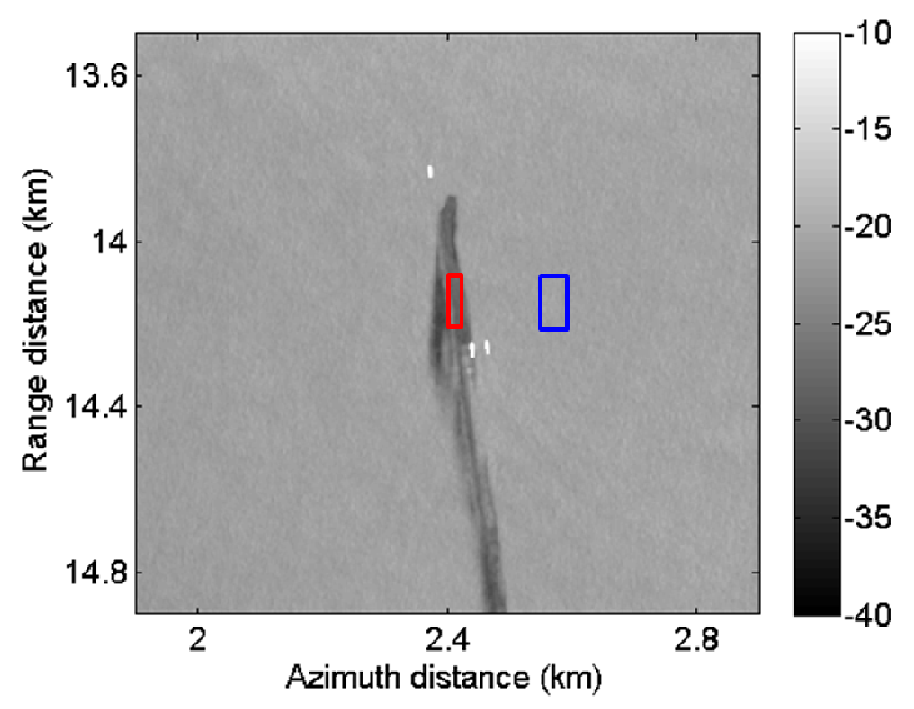

Fig. 10: Areas selected for ROC curves computation - blue box: clean sea surface, red box: slick area - UAVSAR, NOFO'2015 experiment, June 09, 2015 09:56 UTC

ROC graphs shown in Fig. 11 demonstrate that the best performance of detection are given by the cross-polarized channel (HV), followed by VV, PD and $\lambda_{1}$ (the three curves are almost superimposed on Fig. 11), then we found $\mathrm{HH}$ and the Hermitian Product (HP) and finally the conventional quad-polarimetric parameters: Entropy, Polarization Ratio, Degree of Polarization, dual-pol coherence, Bragg Likelihood Ratio and Conformity Coefficient. These results are very close to those obtained by SETHI. 

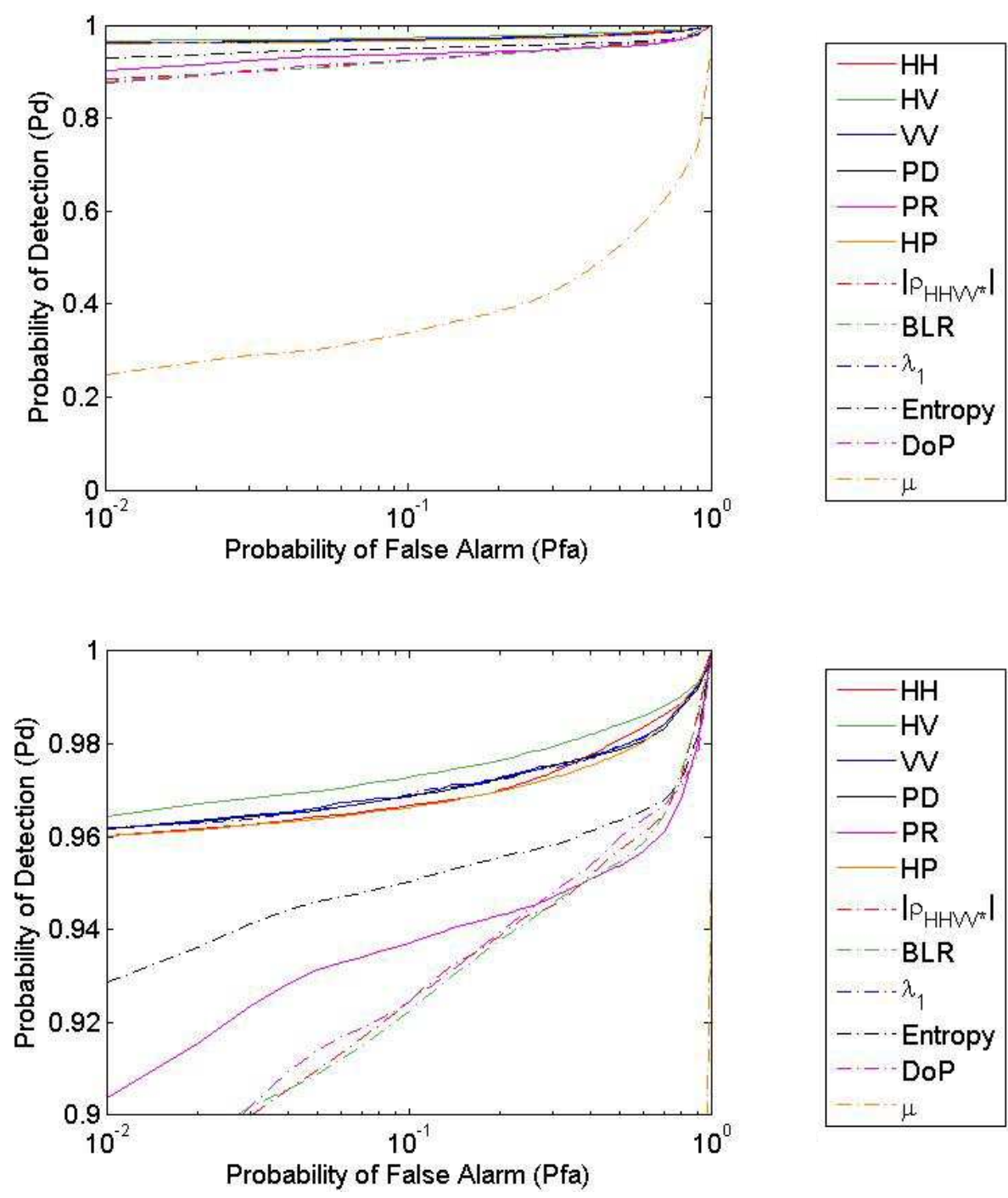

Zoom of the above figure for Pd greater than $90 \%$

Fig. 11: Probability of Detection (Pd) vs Probability of False Alarm (Pfa) computed for all investigated parameters - The top figure is a zoom of the above figure for Pd greater than $90 \%$.

UAVSAR, NOFO'2015 experiment, June 09, 2015 09:56 UTC

\subsection{Evaluation of Polarimetric Parameters for Slick Detection: vegetal oil}

We investigate now Fatty Acid Methyl Esters (FAME) and rapeseed oil releases imaged by SETHI during the POLLUPROOF'2015 experiment (Fig. 12). Because of their physico-chemical properties, these two substances have different behaviors once released into the ocean. FAME forms a cloud in the water column composed by micro-droplets while rapeseed oil remains above the 
surface and produce a film [27]. These two behaviors have been highlighted in [27], using the oilwater mixing index introduced in [26].

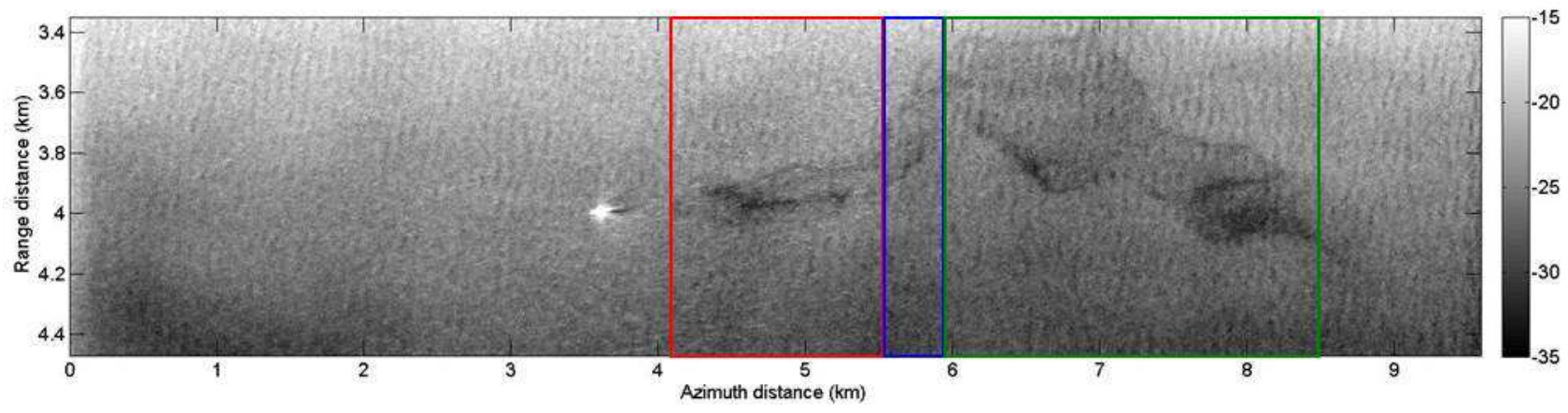

(a): SETHI, L-HH, POLLUPROOF'2015, 22 May 2015, 16:07 UTC

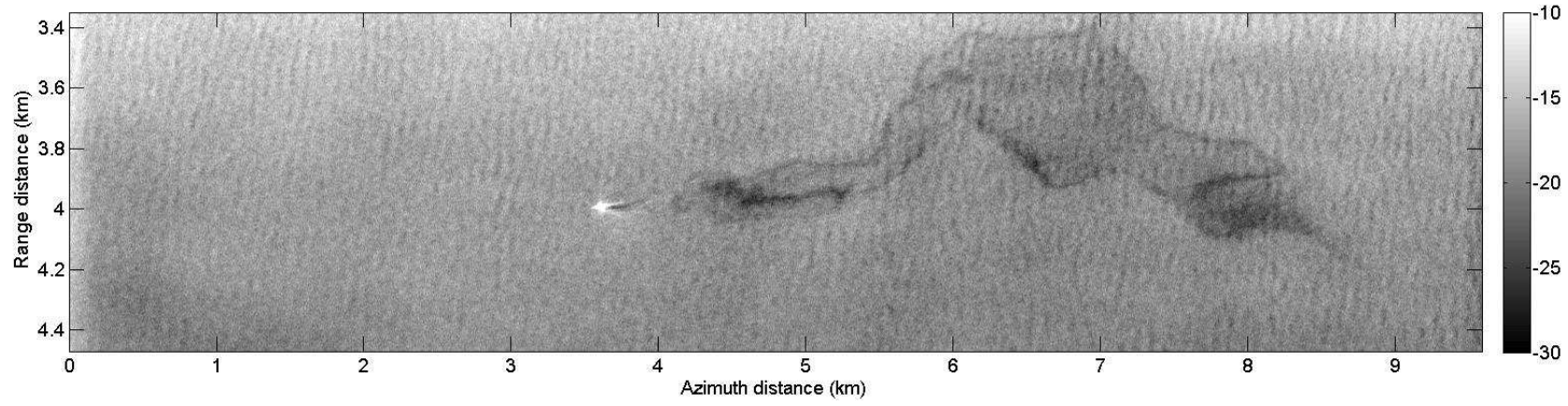

(b): SETHI, L-VV, POLLUPROOF'2015, 22 May 2015, 16:07 UTC

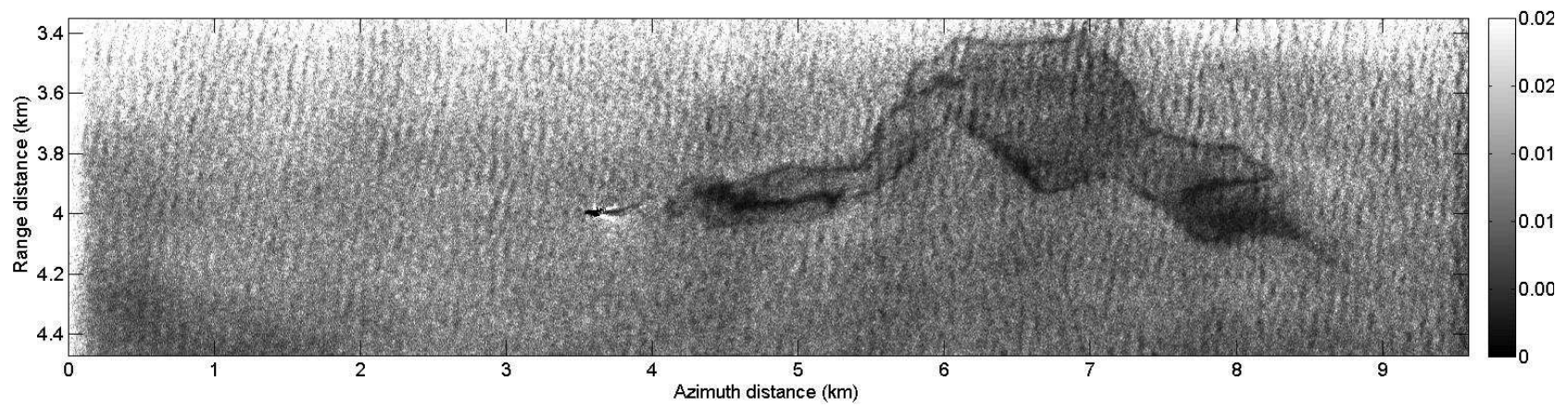

(c): SETHI, L-PD, POLLUPROOF'2015, 22 May 2015, 16:07 UTC

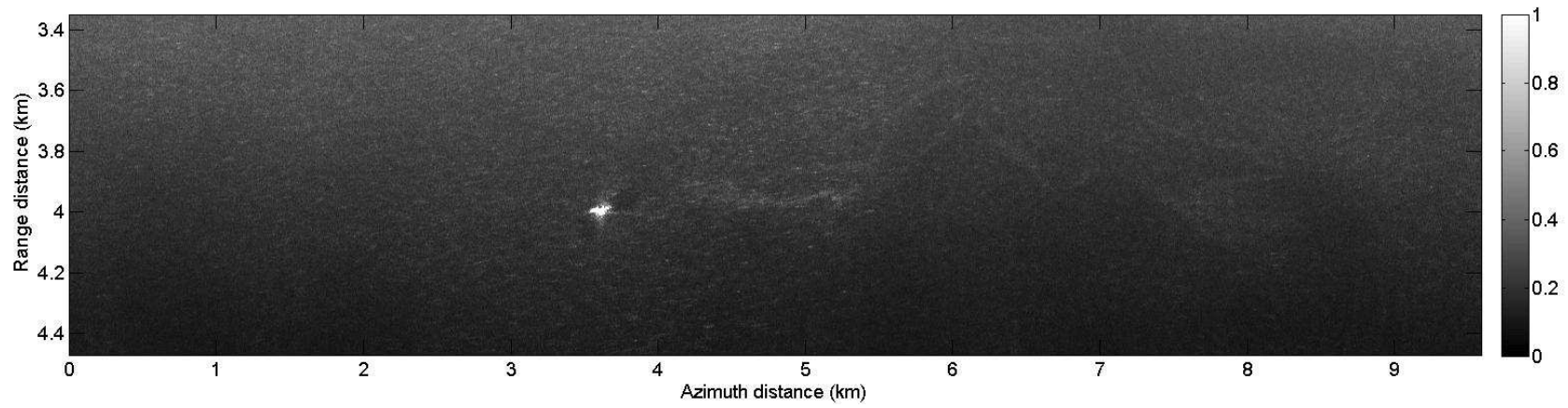


(d): SETHI, L-PR, POLLUPROOF'2015, 22 May 2015, 16:07 UTC

Fig. 12: SETHI POLLUPROOF'2015 - L-band SAR data - May 22, 2015 - 16:07 UTC - HH (a), VV (b), PD (c) and PR (d) quantities - multi-look 7x7 - FAME is indicated by the red box, rapeseed oil by the green box, the blue box corresponds to a mixture between the two products.

The slick contains both substances. FAME appears on the left part of the spill and covers a surface of $0.29 \mathrm{~km}^{2}$ (see red box in Fig. 12). Rapeseed oil corresponds to the right part of the spill (green box in Fig. 12) and covers a surface of $1.26 \mathrm{~km}^{2}$. In between, there is a mixture of the two products (blue box in Fig. 12). From the amount released product $\left(1 \mathrm{~m}^{3}\right)$ and the area covered by the spill, the average thickness of the rapeseed oil spill is estimated to be equal to $0.8 \mu \mathrm{m}$. This is approximately three orders of magnitude thinner than the penetration depth at L-band. Thus, the relative dielectric constant measured by the radar should be unaffected by the oil slick, and as expect, no signature of the rapeseed oil is observed in the PR image (Fig. $12-(d))$.

Clean sea surface and surface covered by rapeseed oil have been chosen and ROC curves computed for the selected areas. As for mineral oil analysis, the SNR is again very high (see Table 6), at least $14 \mathrm{~dB}$, over both covered and free sea surfaces.

TABLE VI

SIGNAL TO NOISE RATIO - SETHI, POLLUPROOF'2015 EXPERIMENT, 22 MAY 2015 16:07 UTC

\begin{tabular}{ccccc}
\hline \hline Region & $\begin{array}{c}\text { Incidence } \\
\text { angle (deg) }\end{array}$ & $\mathrm{HH}$ & $\mathrm{HV}$ & $\mathrm{VV}$ \\
\hline Clean sea & $42.5^{\circ}$ & $30.7 \mathrm{~dB}$ & $18.7 \mathrm{~dB}$ & $36.6 \mathrm{~dB}$ \\
Oil slick & $42.5^{\circ}$ & $26.7 \mathrm{~dB}$ & $14.6 \mathrm{~dB}$ & $33.1 \mathrm{~dB}$ \\
\hline \hline
\end{tabular}

Similarly to that obtained over mineral oil slicks, we observe that over rapeseed oil release most of quad-polarimetric parameters (Bragg Likelihood Ratio, Entropy, co-polarized coherence ...) give very poor performance of detection while amplitude channels are very powerful: HV gives the best performance of detection, followed closely by $\mathrm{HH}, \lambda_{1}, \mathrm{VV}, \mathrm{HP}$ and PD. We note finally that an 
identical ordering of the investigated parameters is obtained when selected sea surface contaminated by FAME instead of rapeseed oil (ROC curves not shown here).
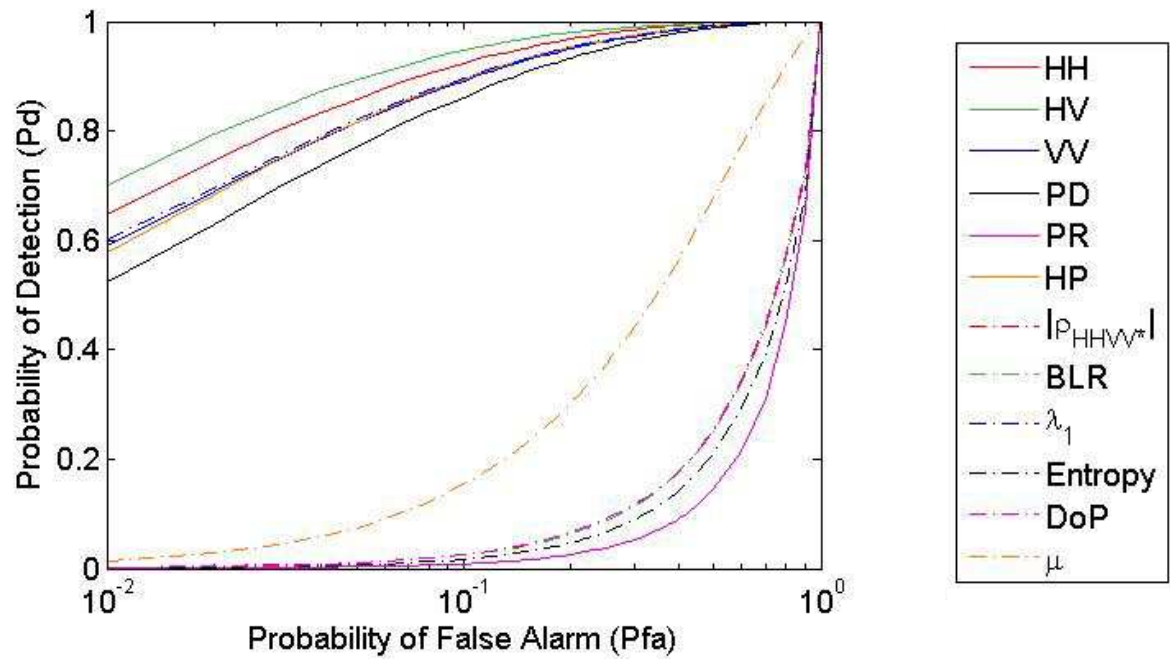

Fig. 13: Probability of Detection (Pd) vs Probability of False Alarm (Pfa) computed for all investigated parameters. SETHI, POLLUPRROF'2015 experiment (rapeseed oil), May 22, 2015

$$
\text { 16:07 UTC }
$$

This analysis, based on ROC graphs obtained with SAR data acquired by two airborne remote sensing sensors, both characterize by a very low instrument noise floor, demonstrate that, in most of the cases, the best performance of detection is given by the VV amplitude channel. Sometimes, a slight improvement could be obtained with the cross-polarized channel (but with the strictly necessary condition of having a very high Signal to Noise Ratio) or with polarization-dependent parameters like the Polarization Difference. When SAR data are collected with a very low NESZ, the backscattered signal is not corrupted by noise, the EM wave is well polarized and only one scattering mechanism occurs over both clean and contaminated sea surface (low entropy values over both surfaces). When the SNR over slick-covered area is not as high as with the airborne acquisitions analyzed here, as for the spaceborne SARs available today, the instrument noise level 
could impact the performance of detection of polarimetric parameters. The paragraph below is then focused on this particular and fundamental aspect.

\subsection{Instrument Noise Effect}

To study how the NESZ impacts the ROC curves obtained for the investigated features, we added increasing levels of white Gaussian noise, from 5 to $30 \mathrm{~dB}$, to the raw SAR data collected by SETHI during the NOFO'2015 experiment. We then processed the noisier data using the standard processing software (Fig. 14). We note that when noise is increased by $15 \mathrm{~dB}$ (Fig. $14-(\mathrm{d})$ ), its effect in the VV image is seen. When $30 \mathrm{~dB}$ of noise is added, the slick is no longer observable in the VV image (Fig. 14 - (f)).

We now assess the detection performance for all simulated instrument noise levels. ROC curves are computed over the areas shown in Fig. 8. Results for some selected radar quantities are given Fig. 15 and conclusions are as follows:

- For a given Pfa, Pd for HH, VV, and HV decrease as SNR decreases. When the additive noise is less than $10 \mathrm{~dB}$, the ROC curves are largely unchanged.

- For a given Pfa, Pd increases for the polarimetric parameters for additive noise values less than

$20 \mathrm{~dB}$. Then, performance of detection decreases with greater levels of additive noise.

Thus, in contrast to the amplitude values, the probability of detection for the polarimetric parameters increases with the instrument noise so long as the SNR is sufficiently high over clean sea surface, and decreases when the SNR over slick-free area becomes low. As SNR decreases, the received signal is increasingly corrupted by noise and the EM wave becomes randomly polarized (DoP goes to 0 and Entropy goes to 1). With sufficiently high noise levels, both contaminated and uncontaminated sea surfaces will be randomly polarized and no further separation between the two regions is possible. SNR values as well as mean value of DoP and Entropy over clean sea and oil slick are given Table 7 and Table 8 below. 


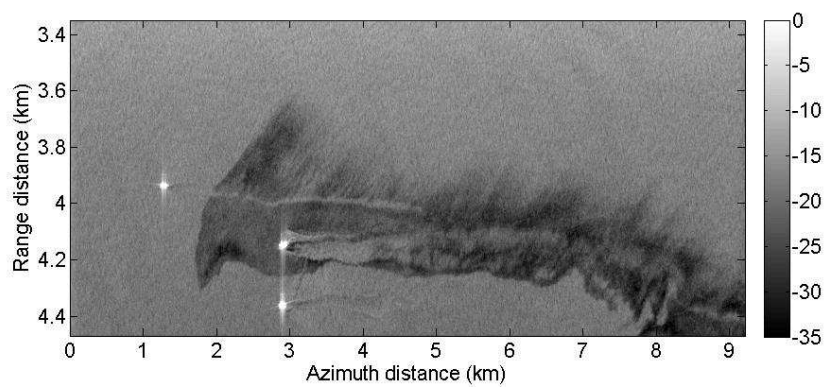

(a): L-band data - SETHI, NOFO'2015 - Original data

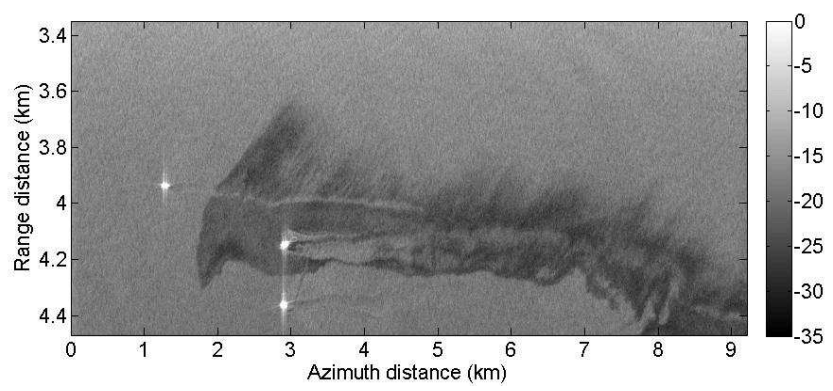

(c): L-band data - SETHI, NOFO'2015 - NESZ + 10dB

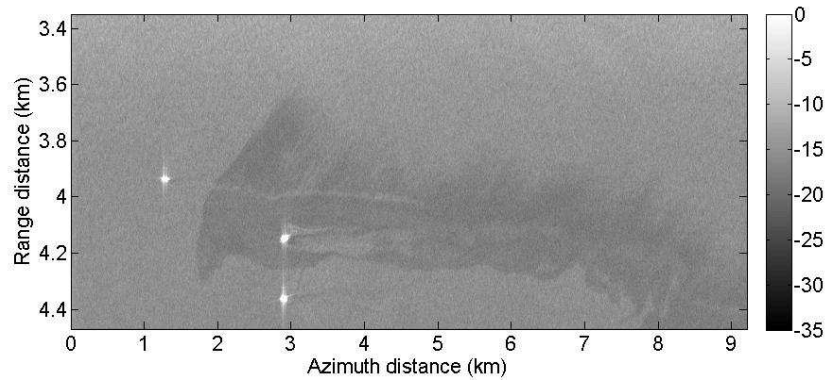

(e): L-band data - SETHI, NOFO'2015 - NESZ + 20dB

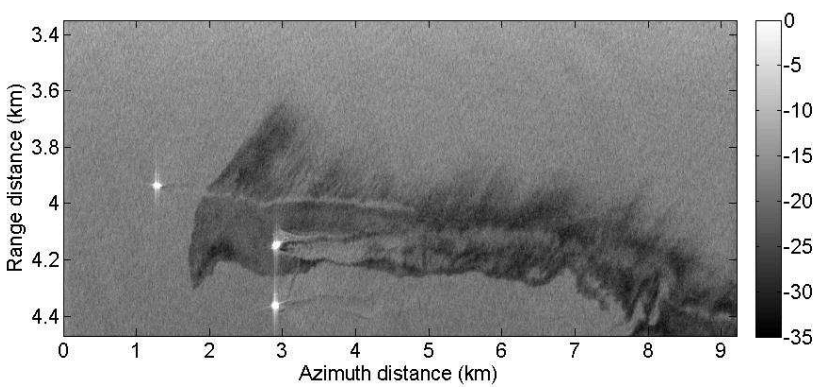

(b): L-band data - SETHI, NOFO'2015 - NESZ + 5dB

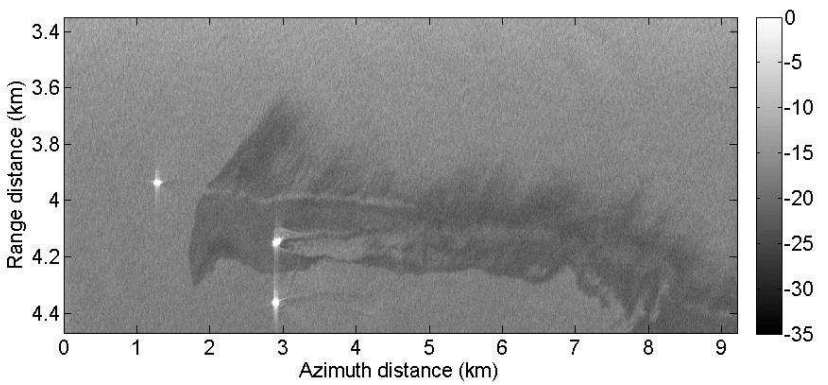

(d): L-band data - SETHI, NOFO'2015 - NESZ + 15dB

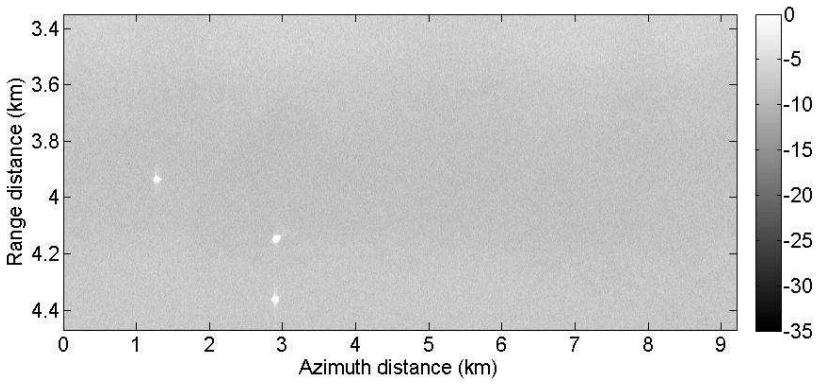

(f): L-band data - SETHI, NOFO'2015 - NESZ + 30dB

Fig. 14: Noise effect - SETHI polarization VV - original data (a) and instrumental noise increased by $5 \mathrm{~dB}$ (b), $10 \mathrm{~dB}$ (c), $15 \mathrm{~dB}$ (d), $20 \mathrm{~dB}$ (e) and $30 \mathrm{~dB}$ (f). - NOFO'2015 experiment, June 09, 2015 10:01 UTC 


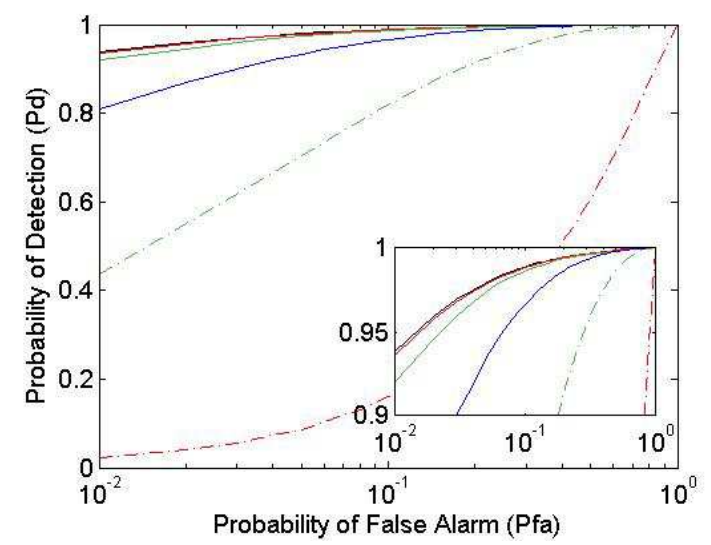

(a): SETHI, NOFO'2015 - HH

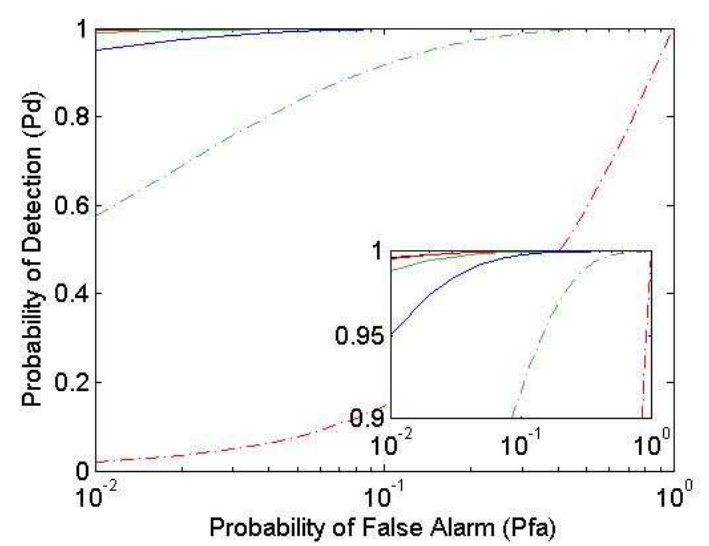

(c): SETHI, NOFO'2015 - VV

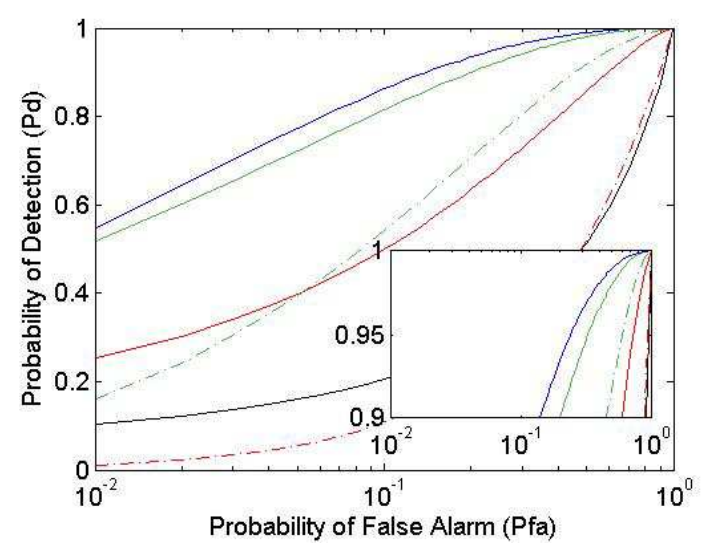

(e): SETHI, NOFO'2015 - DoP
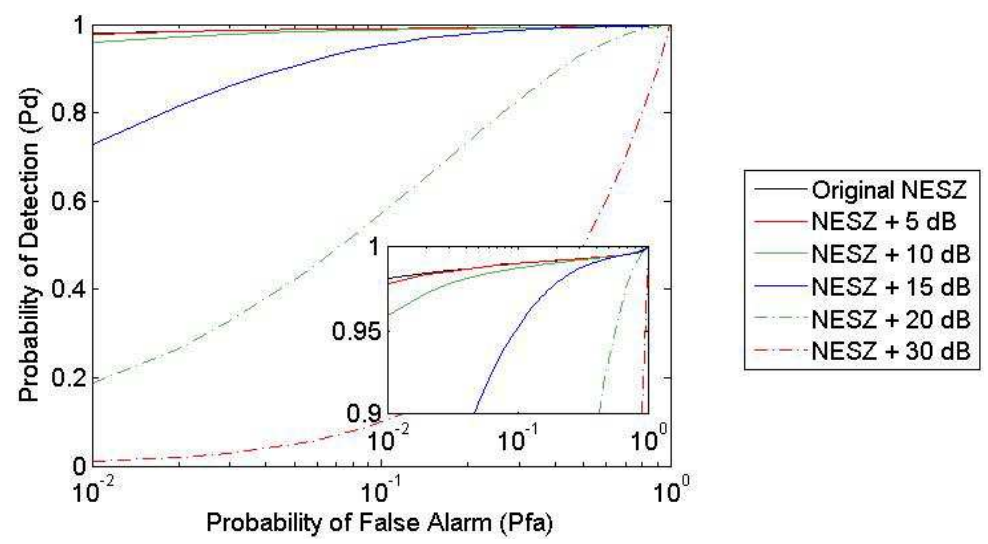

(b): SETHI, NOFO'2015 - HV
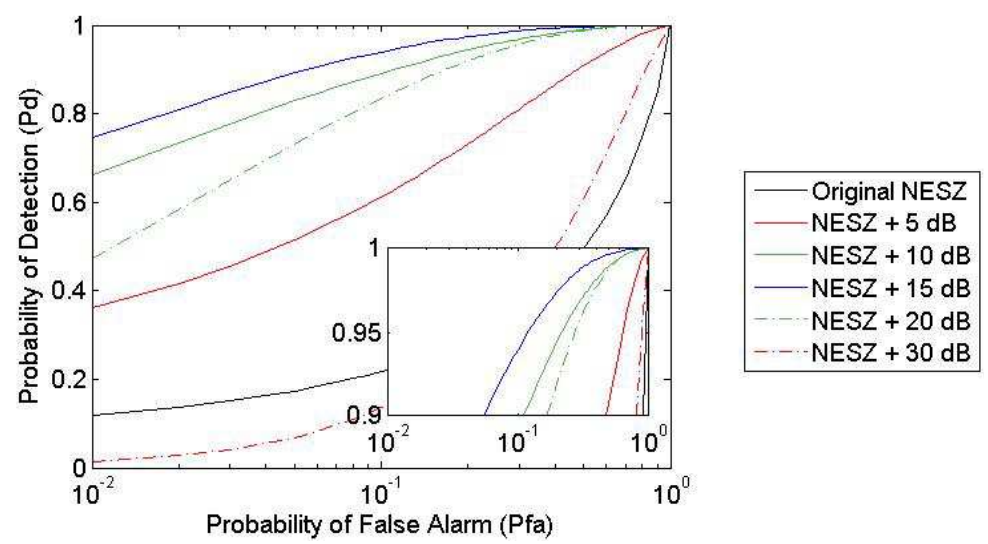

(d): SETHI, NOFO'2015 - $\rho_{\mathrm{HHVV}}$
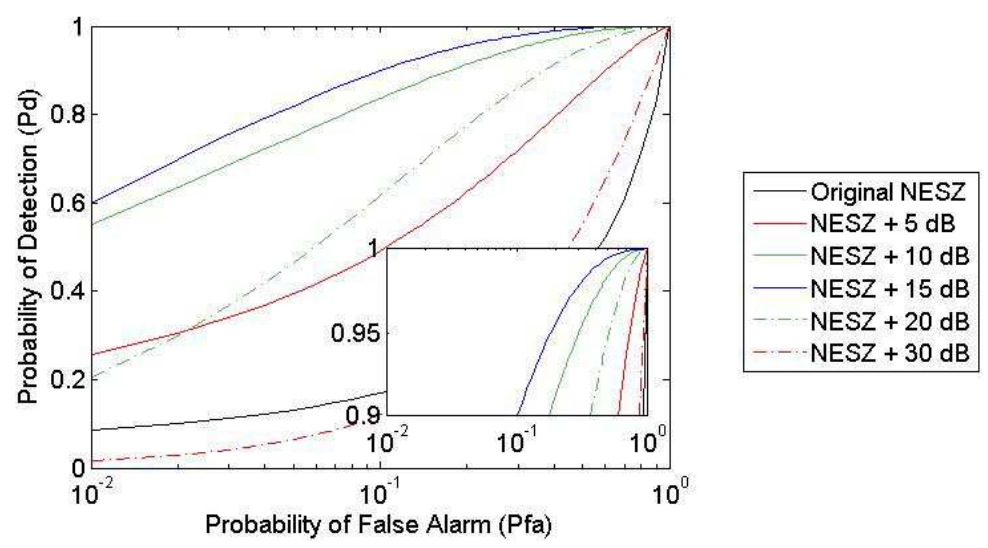

(f): SETHI, NOFO'2015 - Entropy

Fig. 15: Noise effect on ROC curves - SETHI HH (a), HV (b), VV (c), dual-pol coherence (d),

Degree of Polarization (e) and Entropy (f) - NOFO'2015 experiment, June 09, 2015 10:01 UTC 
TABLE VII

SIGNAL TO NOISE RATIO - SETHI, NOFO'2015 EXPERIMENT, 09 JUNE 2015 10:01 UTC

\begin{tabular}{ccccc}
\hline \hline Region & $\begin{array}{c}\text { Noise } \\
\text { added }\end{array}$ & HH & HV & VV \\
\hline \multirow{5}{*}{ Clean sea } & $0 \mathrm{~dB}$ & $26.5 \mathrm{~dB}$ & $16.4 \mathrm{~dB}$ & $34.1 \mathrm{~dB}$ \\
& $5 \mathrm{~dB}$ & $21.5 \mathrm{~dB}$ & $11.4 \mathrm{~dB}$ & $29.1 \mathrm{~dB}$ \\
& $10 \mathrm{~dB}$ & $16.5 \mathrm{~dB}$ & $6.4 \mathrm{~dB}$ & $24.1 \mathrm{~dB}$ \\
& $15 \mathrm{~dB}$ & $11.5 \mathrm{~dB}$ & $1.4 \mathrm{~dB}$ & $19.1 \mathrm{~dB}$ \\
& $20 \mathrm{~dB}$ & $6.5 \mathrm{~dB}$ & $-3.6 \mathrm{~dB}$ & $14.1 \mathrm{~dB}$ \\
& $30 \mathrm{~dB}$ & $-3.5 \mathrm{~dB}$ & $-13.6 \mathrm{~dB}$ & $4.1 \mathrm{~dB}$ \\
\hline \multirow{5}{*}{ Oil slick } & $0 \mathrm{~dB}$ & $21.5 \mathrm{~dB}$ & $10.2 \mathrm{~dB}$ & $28.0 \mathrm{~dB}$ \\
& $5 \mathrm{~dB}$ & $16.5 \mathrm{~dB}$ & $5.2 \mathrm{~dB}$ & $23.0 \mathrm{~dB}$ \\
& $10 \mathrm{~dB}$ & $11.5 \mathrm{~dB}$ & $0.2 \mathrm{~dB}$ & $18.0 \mathrm{~dB}$ \\
& $15 \mathrm{~dB}$ & $6.5 \mathrm{~dB}$ & $-4.8 \mathrm{~dB}$ & $13.0 \mathrm{~dB}$ \\
& $20 \mathrm{~dB}$ & $1.5 \mathrm{~dB}$ & $-9.8 \mathrm{~dB}$ & $8.0 \mathrm{~dB}$ \\
\hline \hline
\end{tabular}

TABLE VIII

DEGREE OF POLARIZATION, ENTROPY SETHI, NOFO'2015 EXPERIMENT, 09 JUNE 2015 10:01 UTC

\begin{tabular}{cccc}
\hline \hline Region & $\begin{array}{c}\text { Noise } \\
\text { added }\end{array}$ & DoP & Entropy \\
\hline \multirow{5}{*}{ Clean sea } & $0 \mathrm{~dB}$ & 0.94 & 0.17 \\
& $5 \mathrm{~dB}$ & 0.93 & 0.19 \\
& $10 \mathrm{~dB}$ & 0.9 & 0.24 \\
& $15 \mathrm{~dB}$ & 0.84 & 0.34 \\
& $20 \mathrm{~dB}$ & 0.75 & 0.46 \\
Oil slick & $30 \mathrm{~dB}$ & 0.67 & 0.56 \\
\hline & $0 \mathrm{~dB}$ & 0.92 & 0.18 \\
& $5 \mathrm{~dB}$ & 0.88 & 0.25 \\
& $10 \mathrm{~dB}$ & 0.81 & 0.36 \\
& $20 \mathrm{~dB}$ & 0.72 & 0.48 \\
& $30 \mathrm{~dB}$ & 0.67 & 0.55 \\
\hline \hline
\end{tabular}

\section{DISCUSSION}

Our analysis of L-band SAR data collected by SETHI and UAVSAR, two airborne sensors that have low instrument noise floor, allows us to formulate the following ordering of polarimetric parameters for region-based slick detection:

- Group 1: VV, HV, PD and $\lambda_{1}$

- Group 2: HH and HP

- Group 3: Entropy, PR, DoP, $\rho_{\mathrm{HHVV}}, \mathrm{BLR}, \mu$ 
The parameters in the first group all provide high performance of detection based on the ROC curve results. The presence of each parameter in group one can be understood through the Braggscattering model. In this framework, VV always has the highest amplitude and HH and VV always have different reflectivities, ensuring that PD takes positive values. In the tilted-Bragg-scattering model, HV has a nonzero amplitude that is always less than both $\mathrm{HH}$ and VV. As a result, the first eigenvalue of the covariance matrix is dominated by VV and, to a lesser extent, $\mathrm{HH}$. The control of $\mathrm{VV}$ on the value of the first eigenvalue explains why the first eigenvalue is a high performing parameter. As previously reported in [18], HV performs well where the instrument noise floor is low because, to a good approximation in the tilted-Bragg model, HV amplitude is proportional to PD.

The second group of parameters, composed of $\mathrm{HH}$ and the Hermitian Product (HP) between $\mathrm{HH}$ and VV channels, gives good performance of detection, although slightly lower than the performance of group 1 . We show that $\mathrm{HH}$ channel is slightly less effective than VV for slick detection, owing to the lower amplitude of $\mathrm{HH}$ relative to $\mathrm{VV}$ in the Bragg-scattering model. However, we emphasize that $\mathrm{HH}$ is effective for distinguishing slicks from relatively clean sea surfaces. HP suffers from the decrease in detection performance of HH compared to VV.

We place all remaining parameters in group 3, which has the worst capabilities of detection. The parameters in group 3 are the co-polarized coherence ( $\left.\rho_{\mathrm{HHVV}}\right)$, Bragg Likelihood Ratio (BLR), Entropy (H), Degree of Polarization (DoP) and Conformity Coefficient $(\mu)$. For these parameters, detection performance seems to be very strongly correlated with the instrumental noise and their interest in a sea pollution detection scheme is instrument-dependent. For a sufficiently high SNR, the EM wave backscattered by the slick-free sea surface remains well polarized (DoP close to 1 and Entropy close to 0) while it becomes less and less polarized over the contaminated area (DoP decreases, Entropy increases) and then performances of detection increase. When the instrumental noise become highly-depredated (low value of SNR), the EM wave becomes likely randomly 
polarized over contaminated and uncontaminated sea surfaces and no further separation between the two regions is possible.

The hierarchy that we propose here is obtained from L-band airborne SAR data collected over vegetable and mineral oil slick released during moderate wind conditions. A similar study is proposed in [16] and [18], with [18] evaluating the parameters during transport and evolution of mineral and plant slicks. The major differences between all these studies being the proposed method of measuring the capabilities of detection of the different quantities investigated and the fact that the slicks studied in [16] and [18] were thinner, formed from the release of $0.2-0.5 \mathrm{~m}^{3}$ of material rather than $45 \mathrm{~m}^{3}$ as the slick in our study. In [16], SAR data acquired by UAVSAR, TerraSAR-X and RADARSAT2 at nearly the same time over mineral oil spills under high wind conditions are investigated using many of the same parameters as herein. They found likewise that VV intensity is the most efficient parameter for slick-sea detection. The HV channel was not investigated in [16] because of the low SNR of the satellite data. The UAVSAR image investigated in [16] are also studied in [18], combined with 17 other images covering the evolving slicks over an 8-hour period. In the latter, the proposed methodology to order the polarimetric parameters is slightly different than in [16], and the authors also found that VV intensity is very efficient for slick-sea discrimination. The HV channel was studied in [18] and, similarly to results obtained herein, they found that the cross-polarized channel is very attractive for slick detection over ocean surface when employed SAR data are acquired with a very low instrumental noise floor. Comparing [16], [18] and the results that we report here, there is a clear consensus on the use of VV or HV channels for slick detection at sea. The main difference between results obtained in this paper and those reported in [16] and [18] concerns the performances of detection given by the Polarization Difference. Indeed, we found here, and as already reported in [15], [17] and [36], that the Polarization Difference is one of the most efficient parameter for slick-sea discrimination. This difference could be due to the different wind conditions, sea state, or slick thicknesses, and highlights the complexity of slick detection across the range of variables under which they can occur. 


\section{CONCLUSIONS}

To guide the selection of the most appropriate SAR imaging mode for marine pollution detection, a methodology based on ROC curves analysis has been reported in this paper. The ROC analysis accounts for the non-Gaussian tails of the probability distribution of parameter values, which are particularly important for the slick-covered areas. We compare the probabilities of detecting a slick to the probabilities of a false alarm for a range of detection thresholds, to rank the various polarimetric parameters in order of slick-detection performance, from best to worst. The originality of the results reported in this paper lies, firstly, in the quantitative evaluation of a dozen of common polarimetric parameters for detecting maritime slicks, and secondly, in the uniqueness of the studied dataset collected by two airborne sensors operating at L-band, both of which are characterized by a very low instrument noise floor, not currently available from spaceborne SARs. This makes the parameters more sensitive to the surface properties and less influenced by the sensor. The third originality of this paper lies in the analysis of the instrument noise effect on the performance of detection offered by the studied parameters. This is done by progressively adding white Gaussian noise directly to the raw SAR data, and then processing the noisier data using the standard processing software.

We find that $\mathrm{HV}$ amplitude can outperform all other investigated amplitudes and polarimetric settings whenever the instrument noise is sufficiently low. However, as instrument noise increases, HV amplitude and all polarimetric parameters that rely on HV become corrupted by noise and their slick-detection performance diminishes. HV is closely followed by the investigated co-polarized settings (ordered in the following: VV, PD, HH and HP), while being more robust to a lower SNR than the cross-polarized channel.

We note that this relative ordering is determined from a single combined set of sea state, meteorological conditions and slick properties, and further work is needed to expand to other conditions, in particular lower wind speeds and different slick thickness. 
For detecting slicks on the sea surface, we think that VV parameter offers the best tradeoff between the benefit of detection performance and the cost instrument and data requirements.

We find that the co-pol amplitudes ( $\mathrm{HH}$ and VV) and two polarimetric parameters, the Polarization Difference and the first eigenvalue of the quad-pol covariance matrix, are more robust in the presence of instrument noise than the cross-pol (HV) amplitude and quad-polarimetric parameters. This disparity in robustness is due to higher co-pol amplitudes relative to the cross-pol amplitude and the strong impact of instrument noise on PolSAR parameters. This implies that polarimetric quantities which combine the four polarimetric channels have performances of detection mainly driven by the NESZ.

\section{ACKNOWLEDGMENTS}

The authors are very grateful to the NOFO (Norwegian Clean Seas Association for Operating Companies) for allowing us to participate in the Oil-on-Water exercise, which was carried out during the period 8-14 June, 2015.

Authors are very grateful to everyone involved in the experiment at sea and those who participated

to SAR data processing. They are also very grateful to $\mathrm{H}$. Oriot from ONERA for successful discussions about ROC curves computation.

Research presented in this paper is part of the POLLUPROOF research program (ANR-13-ECOT007) funded by the French National Research Agency (ANR).

This research was carried out in part at the Jet Propulsion Laboratory, California Institute of Technology, under contract with the U.S. National Aeronautics and Space Administration (NASA). The UAVSAR data are courtesy of NASA/Jet Propulsion Laboratory. 


\section{REFERENCES}

[1] M. Fingas, C. Brown, "Review of oil spill remote sensing", Marine Pollut. Bull. 83, p. 9-23, 2014.

[2] C. Brekke, A. Solberg, "Oil spill detection by satellite remote sensing," Remote Sensing of Environment. ISSN 0034-4257. 95(1), s 1-13, 2005.

[3] M. Gade, W. Alpers, "Using ERS-2 SAR images for routine observation of marine pollution in European coastal waters". Science of the Total Environment 237/238. (1999): S. 441-4480.

[4] O. Garcia-Pineda, B. Zimmer, M. Howard, W. Pichel, X. Li, I. MacDonald, "Using SAR images to delineate ocean oil slicks with a texture-classifying neural network algorithm (TCNNA)," Can. J. Remote Sens., vol. 35, no. 5, pp. 411-421, Oct. 2009.

[5] F. Girard-Ardhuin, G. Mercier, F. Collard, R. Garello, "Operational oil-slick characterization by SAR imagery and synergistic data," IEEE J. Ocean. Eng., vol. 30, no. 3, pp. 487-495, Jul. 2005. G.R. Valenzuela, "Theories for the interaction of electromagnetic and oceanic waves - a review," Boundary-Layer Meteorology, 13(1-4): 61-85, Jan. 1978.

[7] V. Wismann, M. Gade, W. Alpers and H. Huhnerfuss, "Radar signatures of marine mineral oil spills measured by an airborne multi-frequency radar," in Int. J. Remote. Sens. 19, 36073623(1998).

[8] M. Gade, W. Alpers, H. Hühnerfuss, V. Wismann, and P. Lange, "On the reduction of the radar backscatter by oceanic surface films: Scatterometer measurements and their theoretical interpretation," Remote Sens. Environ., vol. 66, no. 1, pp. 52-70, Oct. 1998.

[9] M. Gade, W. Alpers, H. Hühnerfuss, H. Masuko, and T. Kobayashi, "Imaging of biogenic and anthropogenic ocean surface films by the multifrequency/multipolarization SIR-C/X-SAR," J. Geophys. Res., vol. 103, no. C9, pp. 18 851-18 866, 1998.

[10] A. H. S. Solberg, "Remote Sensing of Ocean Oil-Spill Pollution," in Proceedings of the IEEE, vol. 100, no. 10, pp. 2931-2945, Oct. 2012. 
[11] D. Latini, F. D. Frate, and C. E. Jones, "Multi-frequency and polarimetric quantitative analysis of the Gulf of Mexico oil spill event comparing different SAR systems," Remote Sens. Environ., vol. 183, pp. 26-42, Sep. 2016.

[12] S. Skrunes, C. Brekke and T. Eltoft, "Characterization of Marine Surface Slicks by Radarsat-2 Multipolarization Features," in IEEE Transactions on Geoscience and Remote Sensing, vol. 52, no. 9, pp. 5302-5319, Sept. 2014.

[13] A. B. Salberg, Ø. Rudjord and A. H. S. Solberg, "Oil Spill Detection in Hybrid-Polarimetric SAR Images," in IEEE Transactions on Geoscience and Remote Sensing, vol. 52, no. 10, pp. 6521-6533, Oct. 2014.

[14] S. Skrunes, C. Brekke, T. Eltoft and V. Kudryavtsev, "Comparing Near-Coincident C- and XBand SAR Acquisitions of Marine Oil Spills," in IEEE Transactions on Geoscience and Remote Sensing, vol. 53, no. 4, pp. 1958-1975, April 2015.

[15] Ivonin, D. V., S. Skrunes, C. Brekke, and A. Y. Ivanov, "Interpreting sea surface slicks on the basis of the normalized radar cross-section model using RADARSAT-2 copolarization dualchannel SAR images," Geophys. Res. Lett., 43, 2748-2757, 2016.

[16] S. Skrunes, C. Brekke, C. E. Jones and B. Holt, "A Multisensor Comparison of Experimental Oil Spills in Polarimetric SAR for High Wind Conditions," in IEEE Journal of Selected Topics in Applied Earth Observations and Remote Sensing, vol. 9, no. 11, pp. 4948-4961, Nov. 2016.

[17] M. W. Hansen, V. Kudryavtsev, B. Chapron, C. Brekke and J. A. Johannessen, "Wave Breaking in Slicks: Impacts on C-Band Quad-Polarized SAR Measurements," in IEEE Journal of Selected Topics in Applied Earth Observations and Remote Sensing, vol. 9, no. 11, pp. 4929-4940, Nov. 2016.

[18] M. M. Espeseth; S. Skrunes; C. E. Jones; C. Brekke; B. Holt; A. P. Doulgeris, "Analysis of Evolving Oil Spills in Full-Polarimetric and Hybrid-Polarity SAR," in IEEE Transactions on Geoscience and Remote Sensing, vol.PP, no.99, pp.1-21, Apr. 2017. 
[19] F. T. Ulaby, R. K. Moore, and A. K. Fung, Microwave Remote Sensing: Active and Passive. Dedham, MA: Artech House, 1986.

[20] B. Holt, "SAR imaging of the ocean surface," in Synthetic Aperture Radar (SAR) Marine User's Manual, C. R. Jackson and J. R. Apel, Eds. Silver Spring, MD:NOAA, 2004, pp.263-275.

[21] K. Hasselmann, R. K. Raney, W. J. Plant, W. Alpers, R. A. Shuchman, D. R. Lyzenga, C. L. Rufenach, and M. J. Tucker, "Theory of synthetic aperture radar ocean imaging: A MARSEN view," in J. Geophys. Res., 90 (C3) 4659-4686, 1985.

[22] T. Meissner et W. J. Wentz, "The complex dielectric constant of pure and sea water from microwave satellite observations," IEEE Transactions on Geoscience and Remote Sensing, vol. 42, n9, pp. 1836-1849, 2004.

[23] K. Folgerø, "Bilinear calibration of coaxial transmission/reflection cells for permittivity measurement of low-loss liquids, " Measurement Science and Technology, vol. 7, n 9 , pp. 12601269, 1996.

[24] T. Friisø, Y. Schildberg, O. Rambeau, T. Tjomsland, H. Førdedal et J. Sjøblom, "Complex premittivity of crude oils and solutions of heavy crude oil fractions, " Journal of Dispersion Science and Technology, vol. 19, n¹, pp. 93-126, 1998.

[25] B. Minchew, C. E. Jones and B. Holt, "Polarimetric Analysis of Backscatter From the Deepwater Horizon Oil Spill Using L-Band Synthetic Aperture Radar," in IEEE Transactions on Geoscience and Remote Sensing, vol. 50, no. 10, pp. 3812-3830, Oct. 2012.

[26] B. Minchew, "Determining the mixing of oil and seawater using polarimetric synthetic aperture radar," Geophys. Res. Lett., 39, L16607, 2012.

[27] S. Angelliaume, B. Minchew, S. Chataing, P. Martineau and V. Miegebielle, "Multifrequency Radar Imagery and Characterization of Hazardous and Noxious Substances at Sea," in IEEE Transactions on Geoscience and Remote Sensing, vol. 55, no. 5, pp. 3051-3066, May 2017.

[28] Bonn Agreement (2004). Bonn agreement aerial surveillance handbook (pp. 96). 
[29] Bonn Agreement (2009). Bonn agreement aerial surveillance handbook (pp. 106).

[30] I. Leifer, W. J. Lehr, D. Simecek-Beatty, E. Bradley, R. Clark, P. Dennison, Y. Hu, S. Matheson, C. E. Jones, B. Holt, M. Reif, D. A. Roberts, J. Svejkovsky, G. Swayze and J. Wozencraft, "State of the art satellite and airborne marine oil spill remote sensing: Application to the BP oil spill," in Remote Sensing of Environment, Volume 124, 2012, Pages 185-209, ISSN 0034-4257.

[31] M. Fingas, B. Fieldhouse, "Studies on water-in-oil products from crude oils and petroleum products," in Marine Pollution Bulletin, Volume 64, Issue 2, 2012, Pages 272-283, ISSN 0025$326 x$.

[32] Z. H. Shah and Q. A. Tahir, "Dielectric Properties of Vegetable Oils, " in Journal of Scientific Research, vol. 3, n0. 3, pp. 481-492, aug. 2011. ISSN 2070-0245.

[33] U. Erle, M. Regier, C. Persch, and H. Schubert, "Dielectric properties of emulsions and suspensions: Mixture equations and measurement comparisons," in Journal of Microwave Power and Electromagnetic Energy, 35(3):185-190, 2000.

[34] M. Gade, W. Alpers, H. Hühnerfuss, H. Masuko, and T. Kobayashi, "Imaging of biogenic and anthropogenic ocean surface films by the multifrequency/multipolarization SIR-C/X-SAR, " $J$. Geophys. Res., vol. 103, no. C9, pp. 18 851-18 866, 1998.

[35] C. A. Guerin, G. Soriano G., B. Chapron, "The weighted curvature approximation in scattering from sea surfaces," in Waves in Random and Complex Media, 20(3):364-384, 2010.

[36] V. N. Kudryavtsev, B. Chapron, A. G. Myasoedov, F. Collard and J. A. Johannessen, "On Dual Co-Polarized SAR Measurements of the Ocean Surface,"in IEEE Geoscience and Remote Sensing Letters, vol. 10, no. 4, pp. 761-765, July 2013.

[37] H. A. Zebker, J. van Zyl, and D. N. Held, "Imaging radar polarimetry from wave synthesis, " J. Geophys. Res., vol. 92, no. B1, pp. 683-701, Jan. 1987. 
[38] W. J. Plant, E. A. Terray, R. A. Petitt Jr., and W. C. Keller, "The dependence of microwave backscatter from the sea on illuminated area: Correlation times and lengths," J. Geophys. Res., vol. 99, no. C5, pp. 9705-9723, May 1994.

[39] A. S. Milman, A. O. Scheffler, and J. R. Bennett, "A theory of the synthetic aperture radar images of time-dependent scenes, " J. Geophys. Res., vol. 98, no. C1, pp. 911-925, Jan. 1993.

[40] W. Born, E. Wolf, Principles of Optics, 1959, Pergamon.

[41] W.-M. Boerner, H. Mott, E. Luneburg, C. Livingstone, B. Brisco, R. J. Brown, J. S. Paterson, "Polarimetry in radar remote sensing: Basic and applied concepts", in Principles and Applications of Imaging Radar, vol. 2, 1998, Wiley.

[42] R. Touzi, W.-M. Boerner, J.-S. Lee, E. Lueneburg, "A review of polarimetry in the context of synthetic aperture radar: Concepts and information extraction", in Canadian Journal of Remote Sensing, vol. 30, no. 3, pp. 369-379, 2004.

[43] R. Touzi, F. J. Charbonneau, R. K. Hawkins, and P. W. Vachon, "Ship detection and characterization using polarimetric SAR," in Canadian Journal of Remote Sensing, vol. 30, no. 3, pp. 552-559, 2004.

[44] R. Shirvany, M. Chabert and J. Y. Tourneret, "Ship and Oil-Spill Detection Using the Degree of Polarization in Linear and Hybrid/Compact Dual-Pol SAR," in IEEE Journal of Selected Topics in Applied Earth Observations and Remote Sensing, vol. 5, no. 3, pp. 885-892, June 2012.

[45] F. Nunziata, A. Gambardella, M. Migliaccio, "On the degree of polarization for SAR sea oil slick observation", in ISPRS Journal of Photogrammetry and Remote Sensing, Volume 78, April 2013, Pages 41-49, ISSN 0924-2716.

[46] M. Migliaccio, F. Nunziata and A. Buono, "SAR polarimetry for sea oil slick observation", in International Journal of Remote Sensing, 36, 3243-3273, 2015. 
[47] M. L. Truong-Loi, P. Dubois-Fernandez, A. Freeman and E. Pottier, "The conformity coefficient or how to explore the scattering behaviour from compact polarimetry mode," 2009 IEEE Radar Conference, Pasadena, CA, 2009, pp. 1-6.

[48] S. R. Cloude, E. Pottier, "A review of target decomposition theorems in radar polarimetry", in IEEE Transactions on Geoscience and Remote Sensing, vol. 34, no. 2, pp. 498-518, Mar. 1996.

[49] S. R. Cloude, E. Pottier, "An entropy based classification scheme for land applications of polarimetric SAR", in IEEE Transactions on Geoscience and Remote Sensing, vol. 35, no. 1, pp. 68-78, Jan. 1997.

[50] B. Zhang, W. Perrie, X. Li, and W. Pichel, B, "Mapping sea surface oil slicks using RADARSAT-2 quad-polarization SAR image", in Geophys. Res. Lett., vol. 38, L10602, 2011.

[51] C. E. Jones, K.-F. Dagestad, Ø. Breivik, B. Holt, J. Röhrs, K. H. Christensen, M. Espeseth, C. Brekke and S. Skrunes, "Measurement and modeling of oil slick transport," in J. Geophys. Res. Oceans, 121, 7759-7775, 2016.

[52] S. Angelliaume, X. Ceamanos, F. Viallefont-Robinet, R. Baqué, P. Déliot and V. Miegebielle, “ Hyperspectral and Radar Airborne Imagery over Controlled Release of Oil at Sea”, in Sensors, $1772,2017$.

[53] I. Hajnsek, E. Pottier, S. R. Cloude, "Inversion of surface parameters from polarimetric SAR", in IEEE Transactions on Geoscience and Remote Sensing, vol. 41, no. 4, pp. 727-744, Apr. 2003.

[54] S. Hensley et al., "The UAVSAR instrument: Description and first results," 2008 IEEE Radar Conference, Rome, 2008, pp. 1-6.

[55] J.P. Egan, "Signal detection theory and ROC analysis, Series in Cognition and Perception", Academic Press, New York, 1975.

[56] MOS Sweeper - Egersund Group. [Online]. http://www.egersundgroup.no/oilspill/mos-sweeper (accessed on 15 September 2017). 